\title{
LOS FERROCARRILES Y SU IMPACTO SOBRE LA ECONOMÍA COLOMBIANA
}

\author{
MARÍA TERESA RAMÍREZ *
}

Banco de la República de Colombia

\section{RESUMEN}

Recientemente en Colombia ha surgido el interés por explicar los acontecimientos de la historia económica del país dentro del enfoque de la clio. metría. Sin embargo, el análisis del transporte y su influencia sobre el desarrollo económico nacional no ha recibido suficiente atención. Este ensayo busca cubrir tal deficiencia; después de todo, éste es un tema central en el estudio de la historia económica de un país. El trabajo proporciona una nueva base de datos que contribuye al estudio del desarrollo del transporte terrestre en Colombia. El aporte principal del estudio consiste en demostrar que los ferrocarriles no jugaron un papel fundamental en el desarrollo de la economía colombiana.

\section{ABSTRACT}

Recently in Colombia has emerged a new interest in explaining some facts in economic history within the context of cliometrics. However, the analysis of transportation infrastructure and its impact on the Colombian's economic development has not received enough attention. The objective of this paper

$N$ de E: Fecha de recepción del artículo: noviembre 1999.

Fecha de la revisión definitiva: noviembre 2000

Quiero agradecer las sugerencias y comentarios de Lee Alston, Warner Baer, Hadi Esfahani, Adolfo Meisel, Larry Neal y Carlos Pombo a una versión preliminar a este artículo. Se agradece al Banco de la República de Colombia por su ayuda financiera. También se agradece a Rocío Betancourt y Ana María Loboguerrero por su asistencia en la investigación. Una versión en inglés de este artículo fue presentada en Econometric Society, $8^{\text {eb }}$ World Congress, agosto 11-16, 2000, Seattle, Estados Unidos. 
is to close this gap, after all transportation developments is a central topic in the study of country's economic history. This paper provides a new database that contribute to the study of transportation developments in Colombia. The main contribution is to demonstrate that railroads did not play an overwhelming role in Colombia's economy during the first half of the twentieth century.

\section{INTRODUCCIÓN}

En la literatura sobre la historia económica latinoamericana muy pocos estudios han analizado el impacto de los ferrocarriles sobre el crecimiento económico, dentro del marco de la nueva historia económica o cliometría ${ }^{1}$. Este hecho es sorprendente debido a la gran atención que ha recibido este tema dentro de la literatura económica mundial, a partir de los trabajos de R. Fogel (1964) y A. Fishlow (1965). Sólo recientemente en Colombia ha surgido el interés por explicar los acontecimientos de la historia económica nacional dentro de este enfoque ${ }^{2}$. Sin embargo, el análisis del transporte y su influencia sobre el desarrollo económico colombiano no ha recibido suficiente atención ${ }^{3}$. Este ensayo busca cubrir esta deficiencia; después de todo, es un tema central en el estudio de la historia económica del país.

El presente estudio se inscribe dentro del marco de la nueva historia económica, la cual hace uso de la teoría y de técnicas econométricas para explicar los efectos del desarrollo de la infraestructura de transporte sobre el crecimiento económico colombiano. Concretamente, este artículo busca responder, de forma cuantitativa, tres preguntas generales. La primera, ¿Cuál fue el impacto de la reducción en los costos de transporte, como consecuencia de la construcción de los ferrocarriles, sobre el crecimiento económico colombiano? Con este fin, se utiliza la metodología del ahorro social, propuesta por Fogel (1964), y estimaciones de la elasticidad de la demanda del transporte de carga y de pasajeros. La segunda, ¿El desarrollo en la infraestructura de transporte fue determinante en el despegue de las exportaciones cafeteras? Para contestar esta pregunta se utilizan técnicas de series temporales, en particular los Vectores Autorregresivos

${ }^{1}$ Entre las excepciones se encuentran J. Coatsworth (1981), G. Guajardo (1998), W. McGreevey (1975) y W. Summerhill (1996).

${ }^{2}$ Para un resumen de estos estudios, véase A. Meisel (1999).

${ }^{3}$ Entre las excepciones se encuentran, por ejemplo, los trabajos de G. Arias de Greiff (1986), D. Barnhart (1956) y G. Poveda $(1974,1986)$, entre otros. 
(VAR). La tercera, ¿El desarrollo en la infraestructura de transporte ha contribuido a la integración de un mercado nacional? En otras palabras, se busca examinar si las reducciones en los costos de transporte explican reducciones en la divergencia de los precios agrícolas entre las diversas regiones colombianas. Para responder esta pregunta se calculan coeficientes de variación y de convergencia.

El presente trabajo proporciona una nueva base de datos que contribuye al estudio del desarrollo del transporte terrestre en Colombia ${ }^{4}$. En particular, en este trabajo se ensambla una base de datos compuesta con la información sobre longitud de la red, tarifas, volumen de carga y de pasajeros transportados, entre otros, de catorce líneas férreas para el período 1914-1980. También se construye una serie sobre la longitud de las carreteras y se ensamblan series de precios anuales para seis productos agrícolas en las doce ciudades más importantes del país para el período 1928-1990 ${ }^{5}$.

El aporte principal del presente estudio consiste en demostrar que los ferrocarriles no jugaron un papel excepcional en el desarrollo de la economía colombiana.

\section{EL AHORRO SOCIAL GENERADO POR LOS FERROCARRILES Y ESTIMACIONES SOBRE LA ELASTICIDAD PRECIO DE LA DEMANDA DE SERVICIOS DE CARGA Y DE PASAJEROS}

\subsection{El ahorro social}

Antes de la era de los ferrocarriles, que empieza en los últimos años del siglo $\mathrm{XIx}$, las mulas fueron el típico medio de transporte, $\mathrm{y}$ la infraestructura de transporte consistía en caminos reales en malas condiciones, y de escasos ríos navegables no conectados entre sí ${ }^{6}$. La falta de adecuados medios de comunicación causó altos costos de transporte, aislamiento de las regiones y fragmentación de mercados en el país. Por lo tanto, la construcción de los ferrocarriles fue la alternativa para solucionar este problema. Sin embargo, las difíciles condiciones geográficas del país hicieron que

${ }^{4}$ La base de datos está disponible bajo solicitud expresa al autor.

'La construcción de las series se basa principalmente en fuentes primarias, como son, entre otras, las memorias del Ministerio de Obras Públicas al Congreso de la República, los Informes de los Ferrocarriles, el Anuario General de Estadística, y el Anuario Estadístico del Ministerio de Agricultura.

- El río Magdalena constituía el principal medio de transporte fluvial del país. A diferencia de los Estados Unidos, en Colombia no existían sistemas de canales. 
la construcción de los ferrocarriles fuera muy costosa. Además, la falta de recursos económicos y la existencia de mercados de capitales poco desarrollados ocasionaron que el ritmo en la construcción de los ferrocarriles fuera bastante lento. Los primeros ferrocarriles colombianos fueron construidos por razones económicas, principalmente, con el propósito de conectar las regiones productivas del país con el río Magdalena (véase mapa). Por esta razón los ferrocarriles fueron construidos como un sistema complementario al transporte fluvial, y no como sustituto de él. Por lo tanto, los ferrocarriles fueron los sustitutos de las costosas y primitivas formas de transporte terrestre como las mulas y los carros jalados por animales.

De acuerdo con R. Fogel (1964) la metodología del ahorro social consiste en calcular en un año dado la diferencia entre el costo de transportar un volumen de bienes en ese año por los ferrocarriles y el costo de transportar exactamente la misma cantidad de bienes por la forma alternativa de transporte en el supuesto de que el ferrocarril dejara de existir en ese año ${ }^{7}$.

En el presente ensayo, el ahorro social de los ferrocarriles colombianos se calcula para el año $1927^{8}$. Escoger este año se justifica debido a que el Gobierno apoyaba fuertemente la construcción y el mantenimiento de los ferrocarriles, y los sustitutos apropiados del transporte férreo eran aún las mulas y los carros jalados por animales. Adicionalmente, como se aprecia en el Cuadro 1, para 1927 existe la información más completa de tarifas, la cual abarca todos los medios de transporte y tiene la ventaja adicional que provine de una fuente oficial. Por lo tanto, calcular el ahorro social para años anteriores tendría el inconveniente de la falta de disponibilidad de las cifras, lo que podría producir resultados sesgados. Por ejemplo, W. McGreevey (1975) calcula el ahorro social de los ferrocarriles cafeteros en Colombia en 1924 basado en una estimación de la tarifa promedio entre 1845 y 1930 del transporte de carga por mula de $\$ 0.416$ por tonelada-kilómetro. Según el autor, para 1924 el límite inferior de esta tarifa

${ }^{7}$ Esta metodología ha generado controversia debido a que en el cálculo del ahorro social se asume un escenario contrafactual, el cual involucra fuertes supuestos. A pesar de esto, en el presente ensayo se calcula el ahorro social de los ferrocarriles colombianos para mantener el análisis en concordancia con la nueva línea de investigación sobre ferrocarriles, y contrastar de esta forma la experiencia colombiana con la de otros países. Para un resumen de esta controversia, véase $R$. Fogel (1979).

${ }^{8}$ La metodologia del ahorro social ha sido estimada para diferentes países. Por ejemplo, J. Coatsworth (1981) estima el ahorro social en México, W. McGreevey (1975) calcula este ahorro para los ferrocarriles cafeteros de Colombia, A. Gómez Mendoza (1982) para España, W. Summerhill (1996) para Brasil, y G. R. Hawke (1970) para Inglaterra. 


\section{COLOMBIA}

Ferrocarriles en 1925



debía estar en el orden de $\$ 0,5$ por tonelada-kilómetro ${ }^{9}$. De igual forma, el autor calcula que entre 1905 y 1929 la tarifa por ferrocarril era de aproximadamente $\$ 0,15$ por tonelada-kilómetro. Como se observa, debido a la falta de disponibilidad de información, W. McGreevey (1975) calcula

\footnotetext{
${ }^{9}$ Véase W. McGreevey (1975), p. 269.
} 


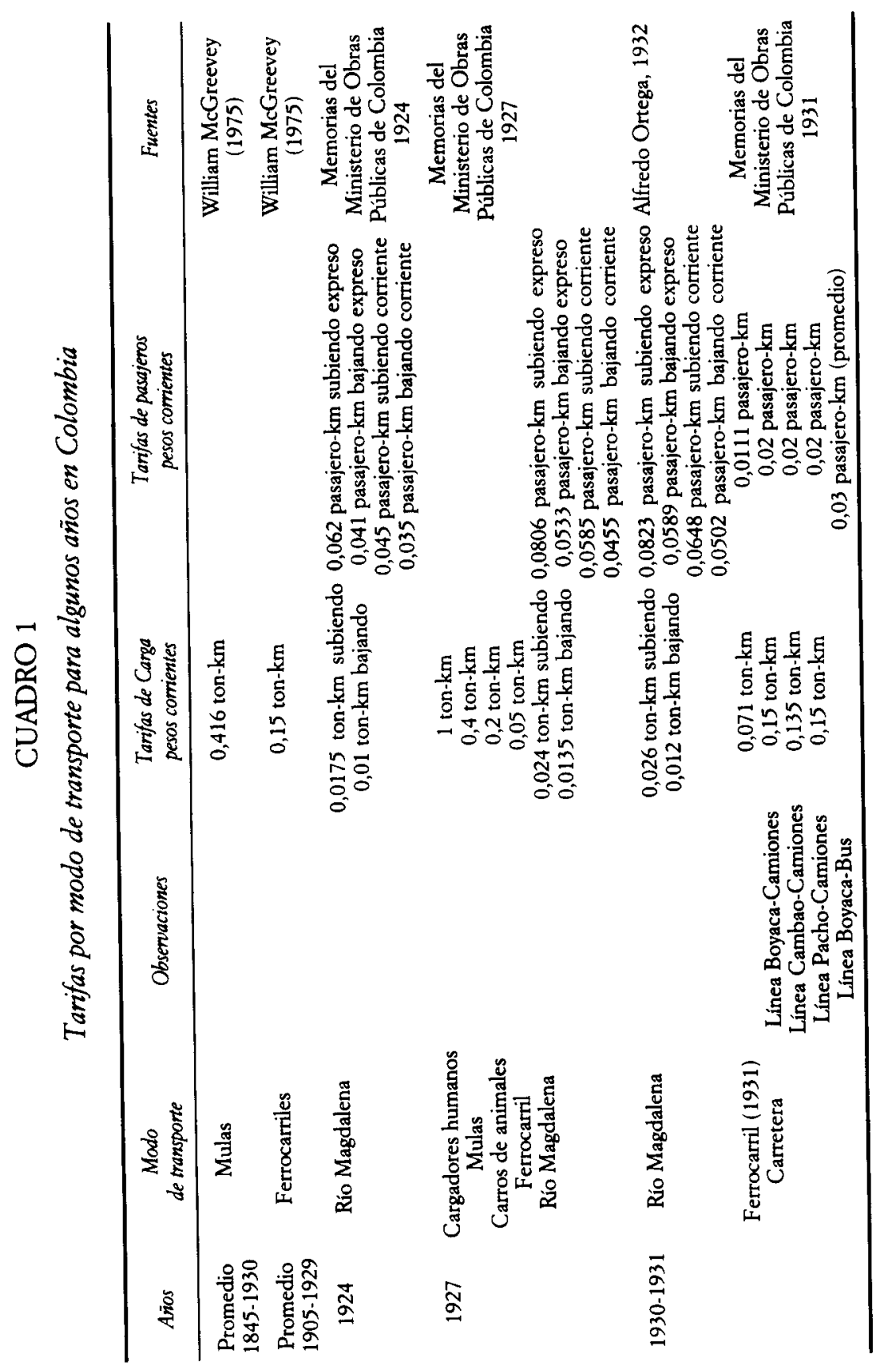




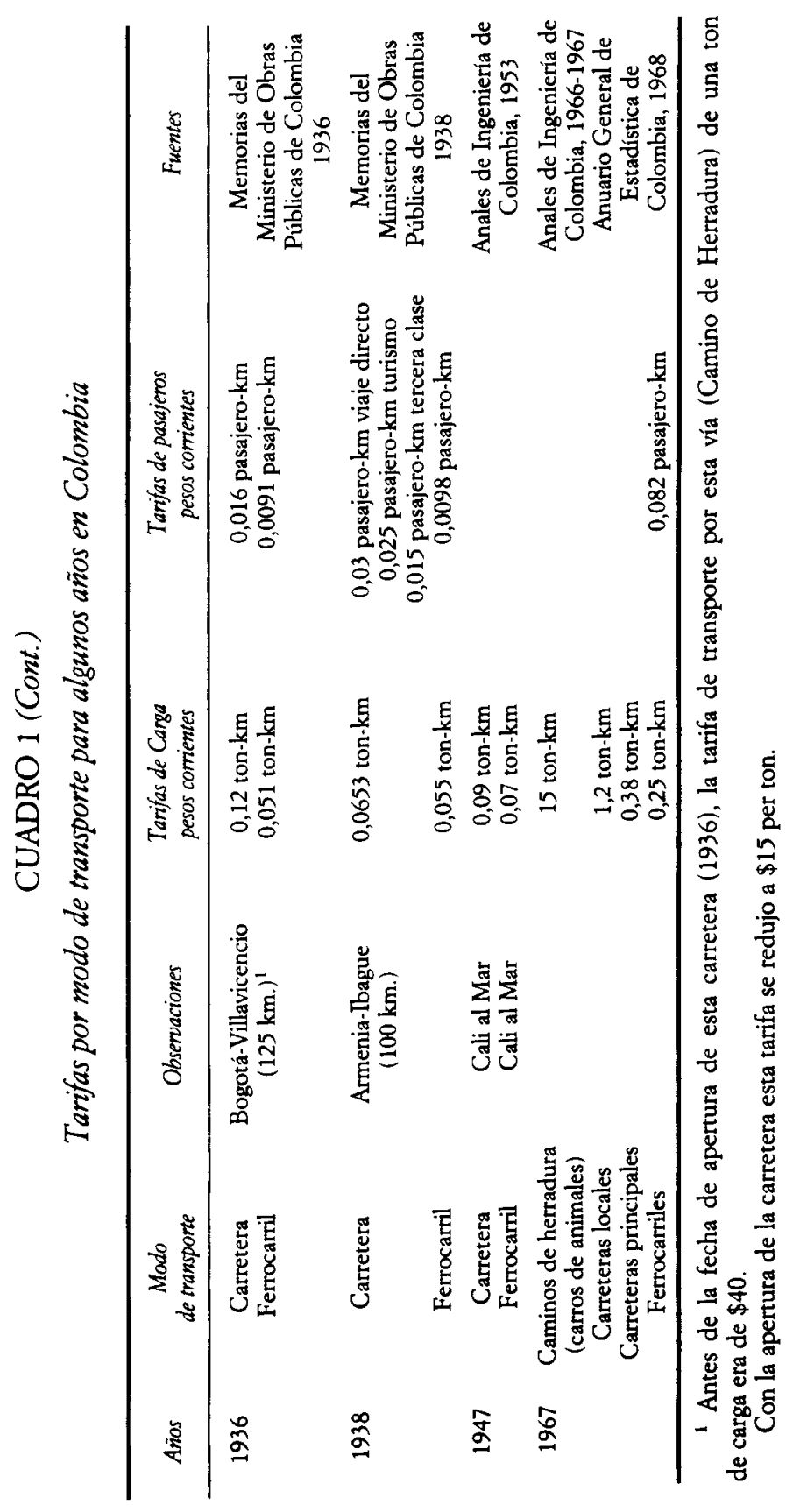


el ahorro social utilizando información de tarifas promedio en diferentes periodos de tiempo. Por lo tanto, la ventaja adicional de calcular el ahorro social en 1927 es que las tarifas tanto de mulas como de ferrocarriles se encuentran disponibles para ese año y su única fuente es el Ministerio de Obras Públicas de Colombia.

De acuerdo con el Cuadro 1, en 1927 la tarifa de carga, medida en toneladas-kilómetro, por modo de transporte era de $\$ 1$ por cargadores humanos, $\$ 0,4$ por mulas, $\$ 0,2$ por carros jalados por animales, $\$ 0,024$ por el río Magdalena, y de $\$ 0,05$ por ferrocarriles. Por lo tanto, la tarifa de carga en carros de animales era cuatro veces superior a la de los ferrocarriles, y la tarifa de las mulas era ocho veces superior. Por otro lado, es importante anotar que el transporte por el río Magdalena era más económico que el transporte férreo. Sin embargo, se prefería el ferrocarril, porque el transporte fluvial resultaba más lento, su uso dependía fuertemente de las condiciones climáticas y no todo su trayecto era navegable.

El Cuadro 2 indica que, en 1927, el ahorro social representaba 7,8 por 100 del PIB, en el escenario donde las mulas eran el modo alternativo de transporte, y 3,4 por 100 del PIB, en el escenario donde los carros de animales era la forma alternativa de transporte ${ }^{10}$. Estas cifras son similares si se comparan con las de los Estados Unidos, entre el 4 por 100 y 9 por 100 del PIB. Sin embargo, estas cifras son bastante menores que las calculadas para países como Brasil (22 por 100 del PIB en 1913) y México (24 por 100 del PIB en 1910) que presentaban condiciones de transporte similares a Colombia en la época anterior a los ferrocarriles (Cuadro 2b) ${ }^{11}$.

De otra parte, una de las principales críticas a la metodología del ahorro social es que en su cálculo se asume una elasticidad precio de la demanda igual a cero. Para corregir este problema R. Fogel (1979) propone ajustar el ahorro social, asumiendo una elasticidad diferente de cero, de la siguiente manera $\frac{S_{t}}{S_{0}}=\frac{\varphi^{1-\varepsilon}-1}{(1-\varepsilon)(\varphi-1)}$ para $\varepsilon \neq 1$, donde $S_{t}$ es el verdadero ahorro

${ }^{10}$ Estas estimaciones son mayores que las calculadas por W. McGreevey (1975) de 3,2 por 100 para los ferrocarriles cafeteros colombianos en 1924.

"Como señala W. Summerhill (1997), a diferencia de Estados Unidos, estos países carecían de ríos navegables, por lo cual antes de la era de los ferrocarriles el medio de transporte prevaleciente eran las mulas. Estos paises poseian condiciones geográficas difíciles que complicaba la comunicación entre las diferentes regiones. Adicionalmente, tanto México, Brasil como Colombia no tenian un mercado de capitales desarrollado que financiara la construcción de los ferrocarriles. 


\section{CUADRO 2}

Estimaciones del aborro social del ferrocarril en el transporte de carga en Colombia, 1927

\section{Modo alternativo de transporte: mulas}
a) Total de carga transportada en ton- $\mathrm{km}$
191 millones ton-km
b) Tarifa por ferrocarril $\$ 0,05$
c) Tarifa por mula.
$\$ 0,40$
d) $\mathrm{a}^{* \mathrm{~b}}$
$\$ 9,55$ millones
e) $\mathrm{a}^{*} \mathrm{c}$
$\$ 76,4$ millones
f) Ahorro Social 1
$\$ 66,85$ millones
g) PIB
$\$ 850$ millones
b) Ahorro Social 1/PIB (\%)
$7,86 \%$

Modo alternativo de transporte: carros de animales

a) Total de carga transportada en ton $-\mathrm{km}$

191 millones ton-km

b) Tarifa por ferrocarril

$\$ 0,05$

c) Tarifa por carros de animales

$\$ 0,20$

d) $\mathrm{a}^{* \mathrm{~b}}$

$\$ 9,55$ millones

e) $\mathrm{a}^{*} \mathrm{c}$

$\$ 38,2$ millones

f) Ahorro Social 2

$\$ 28,65$ millones

g) PIB

$\$ 850$ millones

b) Ahorro Social 2/PIB (\%)

$3,37 \%$

Ahorro Social ajustado por la elasticidad precio de la demanda, $\varepsilon=-0,5$

Ahorro Social 1

Ahorro Social 1/PIB (\%)

$\$ 27,57$ millones

$4,11 \%$

Ahorro Social 2

$\$ 16,42$ millones

$2,25 \%$

Ahorro Social 2/PIB (\%)

FUENTE: Cálculos propios.

social, $\mathrm{S}_{0}$ es el ahorro social calculado bajo el supuesto que $\varepsilon=0$, $\varphi$ es la razón entre la tarifa de la forma alternativa de transporte, mulas, y la tarifa de los ferrocarriles. Siguiendo esta sugerencia, el ahorro social para Colombia se ajusta bajo el supuesto de una elasticidad precio de la demanda de $|0,5|^{12}$. Los nuevos resultados sugieren un ahorro social de 4,11 por 100 del PIB, considerando las mulas como el modo alternativo de trans-

12 Este supuesto es adecuado debido a que los cálculos, en la siguiente sección, de la elasticidad de la demanda para el transporte de carga en Colombia entre 1914 y 1930, se encuentra entre el rango de $-0,44$ y $-0,53$. 


\section{CUADRO $2 b$}

Aborro Social, una comparación internacional

\begin{tabular}{|c|c|c|}
\hline \multicolumn{3}{|c|}{ 1. Asumiendo: $\varepsilon=0$} \\
\hline Autor & Año & $\begin{array}{c}\text { Aborro Social } \\
\text { (\% PIB) }\end{array}$ \\
\hline Fishlow ..................... ante-bellum USA & 1859 & 4 \\
\hline Fogel ....................... USA & 1890 & 8,9 \\
\hline Metzer ...................... Rusia Zarista & 1907 & 4,5 \\
\hline Gómez Mendoza ......... España & 1912 & 19,2 \\
\hline Coatsworth ................. México & 1910 & $24-38,5$ \\
\hline Summerhill ................. Brasil & 1887 & 4,5 \\
\hline Summerhill ................ Brasil & 1913 & 22 \\
\hline McGreevey ................. Colombia (café) & 1924 & 3,2 \\
\hline \multicolumn{3}{|c|}{ 2. Asumiendo: $\varepsilon=-0,5$} \\
\hline Coatsworth ................ México & 1910 & $14,9-16,6$ \\
\hline Summerhill ................. Brasil & 1913 & 11,2 \\
\hline
\end{tabular}

porte, y de 2,25 por 100 del PIB, considerando los carros de animales. Ajustados por la misma elasticidad precio de la demanda el ahorro social de los ferrocarriles mexicanos fue de 16,6 por 100 del PIB en 1910, y para los ferrocarriles brasileños de 11,2 por 100 del PIB en 1913. De nuevo, este resultado indica que las ganancias en crecimiento económico derivadas de una reducción en el costo de transporte en Colombia fueron menores que las de otros países latinoamericanos. Entre las causas que pueden explicar este resultado se puede señalar la escasa longitud y la falta de integración de la red férrea colombiana, lo cual no permitió una completa conexión entre las regiones (véase mapa, p. 85). Así, mientras que en Colombia la relación entre kilómetros de rieles de ferrocarril por 10.000 habitantes, en 1934 era de 3,8, en Brasil y México esta relación era de 8,1 y 14 , respectivamente.

Como se observará en las secciones siguientes, el bajo valor relativo del ahorro social en Colombia respecto a Brasil y México, puede explicarse también por el hecho de que, contrario a estos países, los ferrocarriles colombianos no jugaron un papel abrumador en la expansión de las expor- 
taciones como en México ni en la integración del mercado interno como en Brasil ${ }^{13}$.

\subsection{Estimaciones sobre la elasticidad precio de la demanda de servicios de carga y de pasajeros}

La construcción acelerada de los ferrocarriles colombianos empieza en la década de 1870, con cuatro ferrocarriles, y en la década de 1880 con la construcción de cinco más. Sin embargo, la fiebre en la construcción se detuvo durante la Guerra Civil de los Mil Días (1899-1902) y durante este período muchos de los ferrocarriles ya existentes fueron destruidos o confiscados. Después de la guerra, el presidente Reyes (1905-1910) empieza una política de reconstrucción económica, la cual incluye un programa activo de construcción de ferrocarriles, que fue financiado a través del sistema de concesiones. Durante la década de los años veinte entran en el país los dineros provenientes de la indemnización americana por la separación de Panamá ${ }^{14}$, la cual fue destinada casi en su mayoría (65 por 100) a la construcción de los ferrocarriles. Como consecuencia, la década de los veinte constituye un boom en la expansión de la red ferroviaria del país. Sin embargo, durante la década de los años treinta se produce un cambio radical en la política de transporte en el país al producirse un desplazamiento de las inversiones destinadas a la construcción de los ferrocarriles ${ }^{15}$ hacia la construcción de carreteras. Además, se produce uno de los principales cambios institucionales al crearse el Consejo Administrativo de los Ferrocarriles Nacionales, entidad que tuvo como principal objetivo fijar y estabilizar las tarifas ferroviarias, dado que en el pasado no había existido una clara regulación sobre éstas. La política del Consejo fue fijar las tarifas de acuerdo con el interés público y no de acuerdo con una política de maximización de ganancias. Como consecuencia, las tarifas fueron subsidiadas, lo cual a la postre contribuyó a la quiebra de

${ }^{13}$ De acuerdo con W. Summerhill (1997), las políticas de construcción de ferrocarriles y posteriormente la estructura tarifaria benefició de manera importante el sector exportador en México. De otra parte, el autor señala que los ferrocarriles en Brasil integraron los mercados internos y crearon ganancias de la especialización, lo que contribuyó al crecimiento económico del país.

${ }^{14}$ Durante el Gobierno de P. N. Ospina (1922-1926), Estados Unidos pagó a Colombia $\$ 25.000 .000$ de dólares como indemnización por la separación de Panamá, que tuvo lugar en 1903.

${ }^{15}$ En 1932, la inversión pública en los ferrocarriles nacionales se redujo en un 86 por 100 . 
los ferrocarriles colombianos. En 1954, el Gobierno elimina el Consejo, y nacionaliza completamente los ferrocarriles bajo la administración de la compañía de ferrocarriles nacionales.

Una de las características generales que se observa durante todo el período es la tendencia decreciente, en términos reales, de las tarifas férreas tanto de carga como de pasajeros (Gráfica 1). Por lo tanto, y debido a que

\section{GRÁFICA 1}

Tarifas por ferrocarriles ( $\$$ de 1950 por ton. $-\mathrm{km}$. y pasajero-km.)


FuENTE: Memorias del Ministerio de Obras Públicas, 1920-1965. Alfredo Ortega, 1932. Los Ferrocarriles en cifras, 1959-1981. Anuario de Estadística, 1922-1981. Anales de Ingeniería, 1918-1951. Revista del Consejo Administrativo de los Ferrocarriles, 1932-1934, Ministerio de Transporte, 1995.

los ingresos de los ferrocarriles provenían principalmente de los recaudos por fletes de carga y pasajeros, los ingresos operacionales fueron frecuentemente insuficientes para cubrir todos los gastos operacionales generados por éstos. En efecto, durante los años veinte los ingresos netos permanecen casi constantes, a comienzos de los treinta disminuyen considerablemente, y se recuperan un poco a finales de los treinta y comienzos de los cuarenta, pero a partir de 1945, estos ingresos son siempre negativos (Gráfica 2). En esta sección se plantea la hipótesis que las reducciones en las tarifas 


\section{GRÁFICA 2}

Ingresos operacionales netos de los ferrocarriles (\$1950)

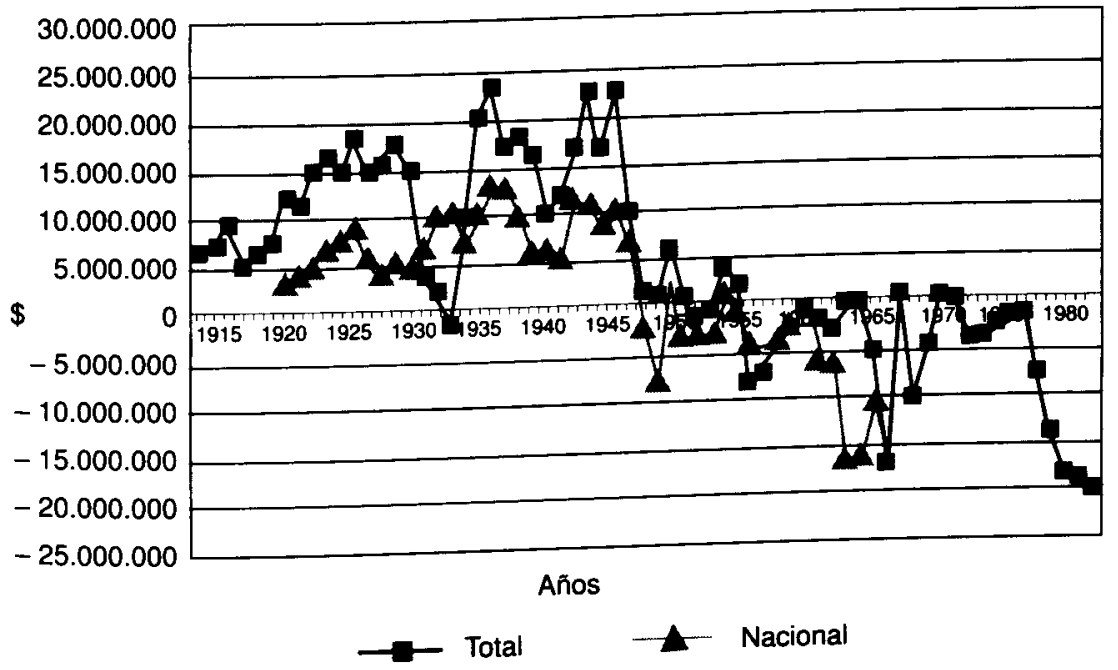

NOTA: Total $=$ Ferrocarriles nacionales + privados.

Fuente: Memorias del Ministerio de Obras Públicas, 1920-1965. Los Ferrocarriles en cifras, 1959-1981. Anuario de Ingeniería, 1918-1951. Anuario General de Estadística, 1922-1981. Revista del Consejo Administrativo de los Ferrocarriles, 1932-1934, Ministerio de Transporte, 1995. Alfredo Ortega, 1932. DNP, 1978. Documento 1.473 UNIF-UIP.

férreas no se vieron compensadas por aumentos en la demanda, hecho que se constituye en una de las principales causas del poco crecimiento de los ingresos de los ferrocarriles.

\subsubsection{Modelo econométrico}

Para verificar la hipótesis, se calcula la elasticidad precio de la demanda partiendo de la siguiente especificación:

$\ln Q_{i t}=\alpha_{0}+\varepsilon \ln P_{i t}+\beta \ln K_{i t}+\gamma \ln Z_{i t}+\alpha_{i}+e_{i t}$,

donde

$Q_{i t}$ es la cantidad total de carga en ton-km.

$P_{i t}$ es el precio real unitario de carga por ton-km. 
$K_{i}$ es el número de kilómetros de los rieles ferroviarios en operación. $Z_{i}$ es un conjunto de variables de control que incluye otros determinantes de la demanda.

$\alpha_{i}$ es el efecto fijo de la compañía $i$.

$\varepsilon$ es la elasticidad precio de la demanda por carga, $\frac{\partial \ln Q}{\partial \ln P}=\varepsilon<0$.

$\beta$ es la elasticidad de la demanda ante cambios en la longitud de la red; $\frac{\partial \ln Q}{\partial \ln K}=\beta>0$.

$e_{i}$ es el residuo con $\mathrm{E}\left[e_{i t}\right]=0, \mathrm{y} \operatorname{Var}\left[e_{i t}\right]=\sigma_{i}^{2}$;

$i$ identifica la compañía y $i=1, \ldots, 14$,

$t$ son los años, $y t=1, \ldots, T$.

En el conjunto de variables $\mathrm{Z}$ se incluye la fecha en que entra en operación cada línea férrea y se espera que las líneas que entran primero sean aquellas que transporten una mayor cantidad de carga y de pasajeros, ya que tuvieron más tiempo para crear su propia demanda ${ }^{16}$. También se introduce una variable dummy para las líneas férreas que tuvieron rieles en la zona cafetera, bajo la hipótesis de que estas líneas transportan un mayor volumen de carga ${ }^{17}$. De otra parte, se incluye la longitud de las carreteras nacionales ${ }^{18}$ para controlar por la competencia inter-modal ${ }^{19}$ y para capturar algunas de las externalidades existentes entre los ferrocarriles y las carreteras. Para capturar algunas de las externalidades de la red se incluyen la longitud del total de la red férrea y la población total de cada departamento en los cuales cada compañía posee rieles. Esta (1996).

${ }^{16}$ La idea de introducir esta variable en la especificación se toma de W. Summerhill

17 W. McGreevey (1975) clasifica los ferrocarriles de Antioquia, Cúcuta, La Dorada, Girardot-Tolima y Pacífico como los ferrocarriles de las zonas cafeteras.

${ }^{18}$ Sería más adecuado utilizar la longitud de las carreteras secundarias debido a que éstas podrían estar localizadas en zonas cercanas, o conectadas, a los ferrocarriles. Por lo tanto, si se utilizara esta serie, la relación de competencia entre carretera y ferrocarril no sería tan clara. Sin embargo, no se encuentra una buena serie sobre la longitud de las carreteras secundarias que permita incluirla en las regresiones. Las estadísticas disponibles son muy esporádicas y poco confiables para ser usadas.

${ }_{19}$ Un mejor indicador de la competencia inter-modal sería la tarifa que los camiones y buses cobran por el servicio de transporte. Sin embargo, no se encuentra disponible una información completa sobre dichos datos. 
última como proxy de la población que está conectada por cada ferrocarril. Finalmente, se incluye el PIB real. La ecuación (1) se utiliza para estimar también la elasticidad precio de la demanda por el transporte de pasajeros, en la cual $Q$ es el total de pasajeros por kilómetro, $P$ es el precio real cobrado por transportar un pasajero-kilómetro.

Se estiman diferentes especificaciones del precio de la demanda de transporte. Inicialmente, se asume que los precios son exógenos, es decir, que no están sujetos a cambios en la oferta. Sin embargo, este supuesto se relaja en estimaciones posteriores al considerar precios endógenos. Estas estimaciones se hacen a través de variables instrumentales que incluyen las tarifas rezagadas, todas las variables exógenas del modelo, una variable dummy que indica si la línea del ferrocarril es de propiedad pública o privada, y una dummy para las diferentes administraciones de los ferrocarriles. Se emplean dos formas funcionales, cuando la elasticidad precio de la demanda es constante, como en la ecuación (1), y cuando no lo es. Adicionalmente, las elasticidades se estiman utilizando dos aproximaciones paramétricas. La primera se basa en una ecuación simple de corte transversal, con paneles no balanceados, en la que se asume que el intercepto es el mismo para todas las compañías férreas. La segunda tiene en cuenta los efectos fijos individuales, por lo cual se asume que el intercepto es diferente entre compañías ${ }^{20}$. El modelo de efectos fijos tiene el inconveniente que elimina todas las variables que son constantes en el tiempo.

\subsubsection{Resultados}

Las estimaciones se dividen en tres sub-períodos de acuerdo con los principales hechos que caracterizaron la evolución de los ferrocarriles en Colombia discutidos anteriormente. Así, el primero comprende los años de 1914 a 1930, en los cuales se presentó un sustancial incremento en la inversión destinada a la construcción de ferrocarriles ${ }^{21}$. El segundo cubre

${ }^{20}$ Los efectos individuales pueden ser fijos o aleatorios. Los aleatorios se excluyen porque no existen suficientes grados de libertad para obtener un estimador consistente, y porque la muestra de individuos es igual a la población. De acuerdo con Green (1993) el modelo de efectos aleatorios es más apropiado cuando se tiene una gran población, luego la muestra de individuos puede ser aleatoriamente extraída de la población total.

${ }^{21}$ En este período se incluyen los ferrocarriles de Antioquia, Barranquilla, Caldas, Cartagena, Norte sección 1 y 2, Cúcuta, Cundinamarca, Girardot, La Dorada, Magdalena, Pacífico, Sur, Nariño y el del Noreste. 
los años treinta hasta mediados de los cincuenta ${ }^{22}$, donde las políticas del Gobierno se tornan en favor de las carreteras, y la política de reducción de tarifas férreas se implementa completamente con la creación del Consejo. El último, desde mediados de los cincuenta hasta principios de los ochenta, donde se completa la nacionalización de los ferrocarriles ${ }^{23}$.

La presencia de efectos fijos se evalúa a través del test de pendiente común, que es un test $F$ basado en la suma de los errores al cuadrado del modelo restringido (simple corte transversal) y el no restringido (efectos fijos) ${ }^{24}$. En este test la hipótesis nula es la existencia de un intercepto común, por lo cual el rechazo de la hipótesis favorece el modelo de efectos fijos. En este caso, los resultados permiten rechazar la hipótesis nula. De otra parte, la forma funcional del modelo se evalúa a través de un test de Wald, el cual no permite rechazar la hipótesis nula de elasticidad precio de la demanda constante. Por lo tanto, la especificación relevante es aquella en donde el parámetro de la elasticidad se estima a través de efectos fijos, utilizando una especificación de elasticidad precio de la demanda constante.

El Cuadro 3 presenta los resultados de las estimaciones de las elasticidades precio de la demanda de transporte férreo de carga y pasajeros. En general, para el periodo completo, la demanda de transporte de pasajero y carga tiende a ser inelástica ante cambios en las tarifas. Por ejemplo, la elasticidad para carga es $-0,71$ y $-0,75$, cuando las tarifas son consideradas exógenas y endógenas, respectivamente. Para los pasajeros, la elasticidad es aún menor $-0,58$ cuando los precios son exógenos y $-0,66$ cuando los precios son endógenos. Los resultados sugieren que las políticas del Gobierno para reducir las tarifas no condujeron a incrementos sustanciales en el volumen de carga y pasajeros transportados. Las tarifas fueron fijadas por debajo del nivel óptimo, debido a que las autoridades fijaron tarifas subsidiadas en lugar de fijarlas de acuerdo con un criterio maximizador de ganancias. Luego, los ferrocarriles operaron en la porción inelástica de sus curvas de demanda.

De otra parte, el servicio de transporte de carga en ferrocarril es elástico al cambio en la longitud de la red [1,6 y 1,3$]$. Sin embargo, el servicio de transporte de pasajeros no lo es $[0,7]$, resultado que puede explicarse

${ }^{22}$ En este periodo se incluyen los ferrocarriles de Antioquia, Barranquilla, Caldas, Cartagena, Norte sección 1 y 2, Cúcuta, Cundinamarca, Girardot, La Dorada, Magdalena, Nordeste, Nariño y el del Pacífico.

${ }^{23}$ En este período se incluyen los ferrocarriles de Antioquia, Atlántico, Centrales, Magdalena y el del Pacífico.

${ }^{24}$ Véase G. Judge et al. (1985) y C. Hsiao (1995). 







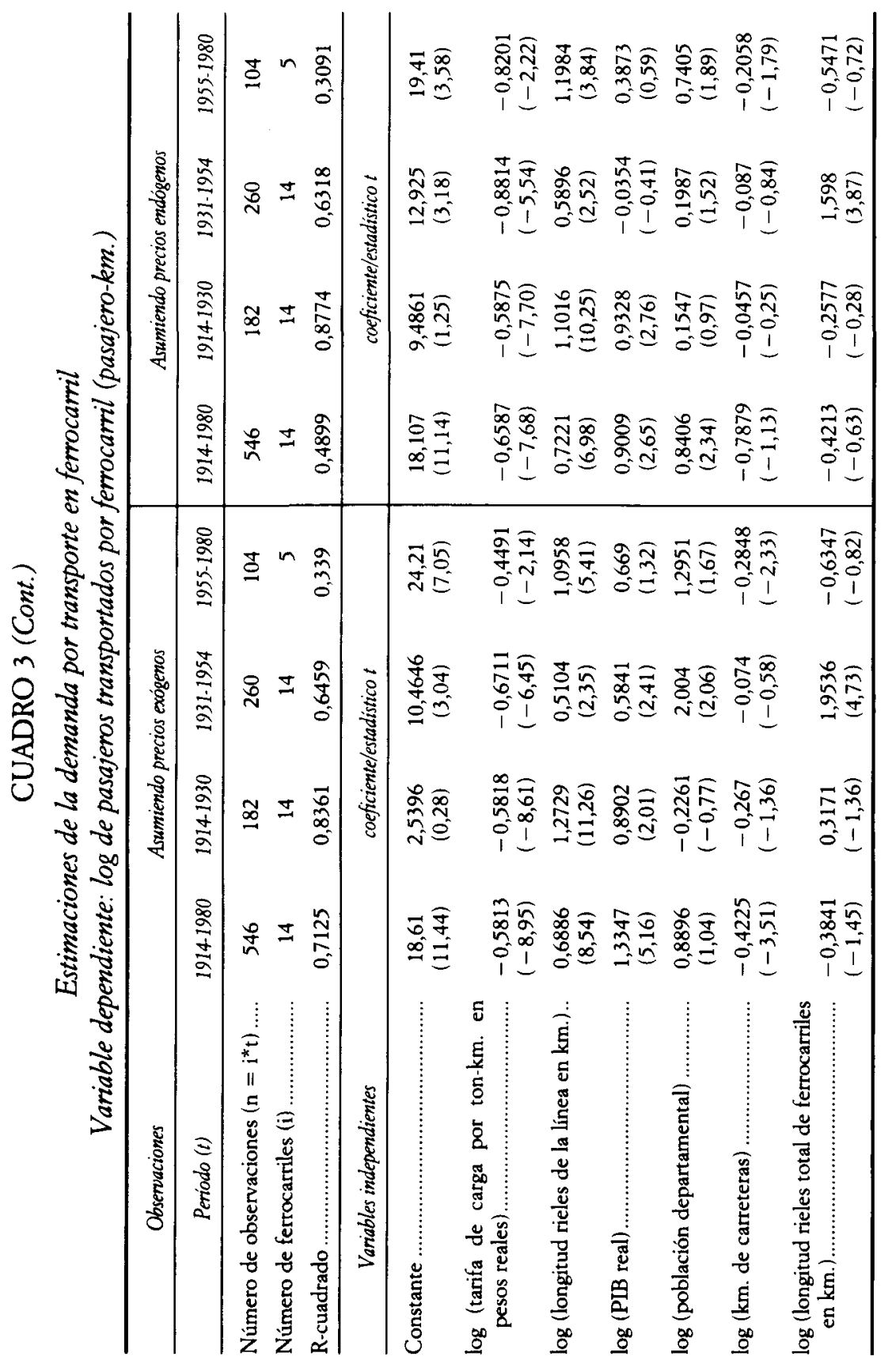


por el hecho de que los ferrocarriles estaban orientados en un mayor grado al transporte de carga y no al de pasajeros. Para entender los resultados de las elasticidades es necesario analizar la actividad de los ferrocarriles también por sub-periodos. Con este fin se utiliza la evolución de los ingresos operacionales de las empresas ferroviarias ${ }^{25}$.

La Gráfica 3 muestra una tendencia positiva en la evolución de los ingresos entre 1915 y $1945^{26}$, sin embargo, en años posteriores la tendencia es decreciente ${ }^{27}$. En particular, entre 1915 y 1930 los ingresos de los ferro-

\section{GRÁFICA 3}

Ingresos operacionales de los ferrocarriles ( $\$ 1950)$

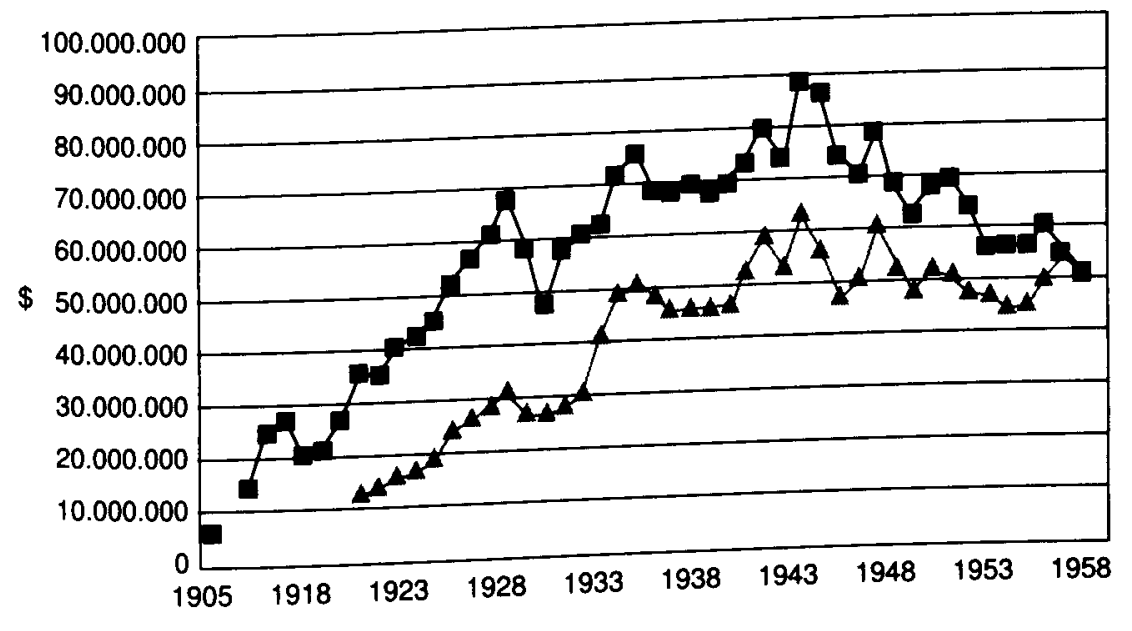

Años

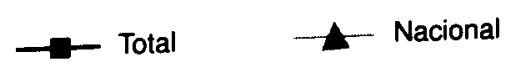

NoTA: Total $=$ Ferrocarriles nacionales + privados.

FuENTE: Memorias del Ministerio de Obras Públicas, 1920-1965. Los Ferrocarriles en cifras, 1959-1981. Anuario de Ingeniería, 1918-1951. Anuario General de Estadística, 1922-1981. Revista del Consejo Administrativo de los Ferrocarriles, 1932-1934, Ministerio de Transporte, 1995. Alfredo Ortega, 1932. DNP, 1978. Documento 1.473 UNIF.UIP.

${ }^{25}$ Véase A. Gómez (1982).

${ }^{26}$ La tasa de crecimiento en el ingreso fue de 5 por 100 para el total de ferrocarriles, y de 8 por 100 para los nacionales.

${ }^{27}$ La nacionalización de los ferrocarriles resultó en reducciones importantes en las tarifas. 
carriles crecieron a una tasa anual de 7,5 por 100 . Pero, entre 1931 y 1946, los ingresos crecieron menos del 3 por 100 por año. Este resultado es sorprendente, debido a que en este periodo entran en operación varios de los ferrocarriles construidos en la década de los años veinte ${ }^{28}, \mathrm{y}$, por lo tanto, es de esperar que las ganancias de los ferrocarriles hubieran aumentado en una magnitud mayor respecto al período anterior. Una causa de este comportamiento se puede encontrar en el hecho de que la política de reducción de tarifas implementada a partir de los años treinta no se vio compensada con aumentos significativos en la demanda. En efecto, la elasticidad estimada para el transporte de carga en el período 1931-1954 es considerablemente menor $[-0,2$ y $-0,4]$ que la estimada para el período 1914-1930 [ $-0,4$ y $-0,5]$. La elasticidad ante cambios en la longitud de la red tanto para carga como para pasajeros también se reduce considerablemente entre los dos períodos. Entre las razones que pueden explicar este hecho se encuentra el desarrollo en la construcción de carreteras durante el segundo periodo. Según Currie (1951), para finales de los años cuarenta, las carreteras a pesar de tener tarifas más altas (Cuadro 1, p. 86) pudieron competir con los ferrocarriles gracias a que el transporte en carretera era más rápido, de mayor calidad, más seguro, con horarios flexibles, $y$ con mayor cobertura que el transporte por ferrocarril ${ }^{29}$. No existen buenas estadísticas sobre el volumen de movimiento de carga y de pasajeros por las carreteras ni series completas sobre el parque automotor colombiano para años anteriores a 1950. Con la información disponible se puede establecer que desde mediados de los cuarenta el transporte por carretera ya ocupaba el primer lugar entre los medios de transporte terrestre tanto para carga como para pasajeros ${ }^{30}$. Es así como en 1947 el volumen de carga transportada, medida en toneladas-kilometros, por carretera era 1,7 veces mayor que el transportado por los ferrocarriles y era 3,8 veces mayor en $1955^{31}$. El Cuadro 4 muestra la forma cómo el transporte por carreteras se expandió en la década de los cuarenta. Por ejemplo, en 1946 el registro de vehículos automotores creció cerca de 28 por 100, los de automóviles 25 por 100 , los de camiones 37 por 100 y el número de autobuses 16 por 100 .

${ }^{28}$ Cuatro ferrocarriles nacionales cuya construcción empezó en la década de los veinte fueron abiertos en 1931 .

${ }^{29}$ L. Currie (1951) señala además que para finales de los años cuarenta «las carreteras transportan una porción cada día mayor de volumen de carga y pasajeros, lo cual contribuye al desarrollo y a la apertura de nuevos sectores en el país", p. 136.

30 Véase L. Currie (1951).

31 Véase M. T. Ramírez (1999), p. 119. 


\section{CUADRO 4}

\section{Vebiculos automotores}

\begin{tabular}{ccccc|cccc}
\hline \multicolumn{4}{c|}{} & \multicolumn{3}{c}{ Tasa de crecimiento (porcentaje) } \\
\hline Años & Total & Automóviles Camiones & Autobuses & Total & Automóviles Camiones Autobuses \\
\hline 1938 & 21.300 & 12.500 & 6.200 & 2.600 & - & - & - & - \\
1939 & 23.400 & 13.700 & 7.000 & 2.700 & 9,86 & 9,60 & 12,90 & 3,85 \\
- & - & - & - & - & - & - & - & - \\
1945 & 29.106 & 15.306 & 10.062 & 3.738 & - & - & - & - \\
1946 & 37.173 & 19.059 & 13.769 & 4.345 & 27,72 & 24,52 & 36,84 & 16,24 \\
1947 & 45.377 & 22.589 & 17.271 & 5.517 & 22,07 & 18,52 & 25,43 & 26,97 \\
1948 & 55.900 & 28.778 & 20.645 & 6.477 & 23,19 & 27,40 & 19,54 & 17,40 \\
1949 & 58.152 & 31.080 & 20.567 & 6.505 & 4,03 & 8,00 & $-0,38$ & 0,43 \\
1950 & 67.343 & 32.164 & 27.441 & 7.738 & 15,81 & 3,49 & 33,42 & 18,95 \\
1951 & 79.021 & 35.459 & 33.544 & 10.018 & 17,34 & 10,24 & 22,24 & 29,46 \\
1952 & 86.013 & 42.451 & 33.544 & 10.018 & 8,85 & 19,72 & 0,00 & 0,00 \\
1953 & 97.733 & 51.305 & 36.521 & 9.907 & 13,63 & 20,86 & 8,87 & $-1,11$ \\
1954 & 127.502 & 67.560 & 47.798 & 12.144 & 30,46 & 31,68 & 30,88 & 22,58 \\
\hline
\end{tabular}

Fuente: L. Currie (1951): Bases de un Programa de Fomento para Colombia; J. Lebret (1958): Misión de Economia y Humanismo.

De otra parte, el comercio internacional de Colombia se redujo como consecuencia de la depresión de la economía mundial de los años treinta y la guerra mundial en los años cuarenta. Por lo tanto, los ferrocarriles no pudieron crear una nueva demanda, ni sostener los niveles de los años anteriores. Los resultados permiten concluir que la economía respondió en un mayor grado a las primeras expansiones de los ferrocarriles, mientras que las últimas expansiones tuvieron un impacto menor.

El último período corresponde a 1955-1980, en el cual la red de ferrocarriles se nacionalizó completamente. La mayor elasticidad puede explicarse por la entrada en operación en 1961 del ferrocarril del Atlántico que conectó regiones estratégicas, como la costa atlántica, con Bogotá.

En cuanto a las restantes variables se encuentra que la expansión de las carreteras nacionales afecta negativamente ${ }^{32}$ el volumen de carga transportada por ferrocarril. Como se mencionó anteriormente, las carreteras nacionales competían con los ferrocarriles en cuanto a calidad y cobertura

${ }^{32}$ Como se mencionó anteriormente, es probable que se hubiera encontrado una relación contraria si se hubieran incluido en las estimaciones las carreteras secundarias debido a que éstas podrían ser complementarias de los ferrocarriles en vez de sustitutas. 
del servicio. En general el PIB real tiene un efecto positivo y significativo en el transporte férreo. Por el contrario, las variables que se introducen para capturar externalidades de la red, como la población departamental y la longitud total de la red férrea, no resultaron significativas. Tal vez, la inclusión del número de estaciones por línea férrea, equipos de señales, número de locomotoras y vagones, hubiera sido más apropiada para capturar la calidad de la red y, por lo tanto, las externalidades. Sin embargo, los datos encontrados sobre estas variables son muy esporádicos para ser utilizados en las estimaciones.

Finalmente, a partir de los resultados econométricos se puede concluir que la política del Gobierno en cuanto al manejo de las tarifas fue populista y antieconómica. Esta política de reducción de tarifas no se vio compensada con aumentos sustanciales en la demanda, hecho que en el largo plazo contribuyó a la quiebra económica de los ferrocarriles.

\section{RELACIÓN ENTRE LOS FERROCARRILES Y EL SECTOR EXPORTADOR EN COLOMBIA: EL CASO DEL CAFÉ}

Los historiadores económicos han enfatizado la existencia de una estrecha relación entre el desarrollo de los ferrocarriles y el aumento de las exportaciones de café en Colombia, y han calificado este vínculo como indispensable (Beyer, 1947; McGreevy, 1975; Urrutia, 1979, y Poveda 1986, entre otros). La literatura ha enfatizado esta relación debido a que los primeros ferrocarriles fueron construidos con el propósito de transportar café a los puertos para su exportación. Por ejemplo, el ferrocarril de Cúcuta, construido en 1888 , recorría una de las principales zonas cafeteras de la época. Por lo cual, para hacer competitivas las exportaciones de café de las otras regiones era necesario la expansión de los ferrocarriles y de esta forma reducir el costo de transporte del grano ${ }^{33}$.

Históricamente, desde finales del siglo xIX hasta comienzos de 1990, el café ha sido el principal producto exportado del país ${ }^{34}$. La expansión de la producción de café empieza a finales de 1880 , y para 1898 representaba más del 50 por 100 del total de exportaciones. Sin embargo, la producción del grano decrece durante la Guerra Civil de los Mil Días (1899-1902), y solamente a mediados de la década de 1910 las expor-

${ }^{33}$ Véase M. Urrutia (1979) y G. Poveda (1986).

${ }^{34}$ El café representó entre 1942 y 1962 más del 80 por 100 del valor total de las exportaciones y entre 1962 y 1985 el 50 por 100 . 


\section{CUADRO 5}

Kilómetros de rieles utilizados para transportar café en Colombia, 1898-1950

\begin{tabular}{|c|c|c|c|}
\hline Años & $\begin{array}{c}\text { Longitud total } \\
\text { de rieles de ferrocarril } \\
\mathrm{km}(a)\end{array}$ & $\begin{array}{c}\text { Longitud de rieles } \\
\text { destinados a transportar café } \\
\mathrm{km}(\mathrm{b})\end{array}$ & $\begin{array}{c}(b) /(a) \\
\text { (porcentaje) }\end{array}$ \\
\hline $1898 \ldots \ldots \ldots \ldots$ & 593 & 423 & 71,33 \\
\hline $1914 \ldots \ldots \ldots \ldots$ & 1.143 & 919 & 80,40 \\
\hline $1922 \ldots \ldots \ldots \ldots$ & 1.571 & 1.382 & 87,97 \\
\hline $1933 \ldots \ldots \ldots \ldots$ & 2.892 & 1.943 & 67,19 \\
\hline $1937 \ldots \ldots \ldots \ldots$ & 3.060 & 1.928 & 63,01 \\
\hline $1949 \ldots \ldots$ & 3.426 & 2.246 & 65,56 \\
\hline
\end{tabular}
у 1949.

FUENTE: Robert Beyer (1947) para 1898, 1914, 1922, y estimaciones para 1933, 1937

taciones de café alcanzan de nuevo los niveles observados en 1898. Los períodos de expansión del café coinciden con el impulso en la construcción de los ferrocarriles. R. Beyer (1947) estima que el 71 por 100 del total de kilómetros de ferrocarril construidos en 1898 , y el 80 por 100 en 1914 , se utilizaron en el transporte de café (Cuadro 5). De hecho, las exportaciones del grano representaron más del 70 por 100 del total de carga transportada por el ferrocarril de Antioquia en 1895, por el de Girardot en 1908, y por el de Barranquilla en 1891. Estos datos han sido utilizados ${ }^{35}$ para resaltar la influencia de los ferrocarriles en la expansión del sector cafetero. Sin embargo, la extensión de los rieles en el país era escasa y existía una separación física entre las líneas férreas. Por lo tanto, la interpretación de estos datos debe realizarse con cuidado. Por ejemplo, de acuerdo con M. Palacios (1980), en la segunda década del siglo XX las mulas continuaban siendo el principal medio de transportar café.

La Gráfica 4 indica que la cantidad absoluta de café transportada en tren ${ }^{36}$ presenta una tendencia decreciente. Una de las razones que puede explicar este descenso es que con el transcurso del tiempo las carreteras empezaron a competir con los trenes. Además, el puerto de Buenaventura, en el Pacífico, se convirtió en el puerto más importante para las expor-

${ }^{35}$ Véase G. Poveda (1986).

36 Incluye el volumen de café transportado por los ferrocarriles de Antioquia, Barranquilla, Caldas, Cúcuta, Cundinamarca, La Dorada, Girardot, Nariño, Nordeste, Norte y Pacífico. 


\section{GRÁFICA 4}

Cantidad de café transportada por los ferrocarriles



Fuente: Anuario General de Estadística de Colombia. Los Ferrocarriles en cifras. Memorias del Ministerio de Obras Públicas y Transporte, varios años.

taciones de café. De hecho, en 1950 más del 50 por 100 de las exportaciones de café se desplazaron por el ferrocarril del Pacífico a Buenaventura. Esto produjo una caída en la importancia de los demás ferrocarriles. Estadísticas disponibles indican que la participación del grano dentro del total de carga transportada por el ferrocarril de Antioquia pasó de 70 por 100 en 1895 a 20 por 100 en 1933 y a 7 por 100 en 1950 , y la del ferrocarril de Girardot lo hizo de 70 por 100 en 1908 a 7 por 100 en $1950{ }^{37}$.

En resumen, al menos durante los primeros años del siglo, los ferrocarriles jugaron un papel importante en la expansión de las exportaciones cafeteras debido principalmente a que los primeros fueron construidos para transportar el grano hacia los puertos. Por lo tanto, no se busca determinar la existencia de una relación entre ferrocarriles y exportaciones de café, sino que se parte del hecho de que sí existió tal relación. Lo que se busca responder es ecuál fue el alcance de los trenes sobre la expansión de las exportaciones de café?

${ }^{37}$ Cálculos propios, con base en la información registrada en el Anuario General de Estadística, varios números. 


\subsection{Metodología y resultados}

Para responder la pregunta anterior se emplean técnicas de series temporales como el test de causalidad de Granger y estimaciones de vectores autorregresivos (VAR). El análisis se limita al período 1905-1955 por dos razones. Primero, durante la Guerra Civil de los Mil Días (1899-1902) grandes extensiones de plantaciones de café fueron destruidas, la construcción de ferrocarriles se paralizó, y las empresas férreas detuvieron sus operaciones. Segundo, a partir de los años cincuenta el 50 por 100 de los ferrocarriles fueron clausurados y los restantes fueron nacionalizados, por lo cual el transporte de carga por tren perdió participación dentro del total de carga terrestre.

El test de Granger se utiliza para verificar la existencia de una relación de causalidad, y determinar cuál fue la dirección entre la expansión de la red férrea (longitud en kilómetros de la red) y la expansión en las exportaciones cafeteras (sacos de café de 60 kilogramos). Los resultados presentados en el Cuadro 6 sugieren la existencia de una relación de causalidad en ambas direcciones ${ }^{38}$. Es decir, las exportaciones de café ayudaron a explicar las expansiones en el sistema férreo, y los trenes ayudaron a explicar la expansión de las exportaciones de café. Este resultado no es sorprendente porque, como se mencionó anteriormente, los primeros ferrocarriles se construyeron precisamente para transportar café hacia los puertos para luego exportarlo. Adicionalmente, el café fue la carga de compensación de los ferrocarriles que le garantizaban su rentabilidad económica, al menos durante los primeros años de funcionamiento.

El siguiente sistema de vectores autorregresivos (VAR), permite estudiar las interrelaciones dinámicas entre las exportaciones de café y la longitud de la red férrea.

$$
\begin{aligned}
& y_{t}=\alpha_{1}+A_{11}(\mathrm{~L}) y_{t-1}+\mathrm{A}_{12}(\mathrm{~L}) x_{t-1}+\mathrm{t}+\mu_{1 t} \\
& x_{t}=\alpha_{2}+A_{21}(\mathrm{~L}) y_{t-1}+A_{22}(\mathrm{~L}) x_{t-1}+\mathrm{t}+\mu_{2 t}
\end{aligned}
$$

${ }^{38}$ Se realizó el test de Dickey y Fuller Aumentado (ADF) para verificar la existencia de raíces unitarias en las series. El resultado del test permite rechazar la hipótesis nula de una raíz. Es necesario también determinar el rezago óptimo y establecer la normalidad de los residuos. Para determinar el rezago óptimo se emplearon los criterios de información de Akaike, Schwarz y Hannan-Quinn, los cuales sugieren que éste debe ser igual a uno. Una vez establecido el orden se revisó si los residuos eran ruido blanco y se determinó si el proceso de ruido blanco multivariado era normal. Con este objetivo el test de normalidad multivariado basado en el momento (skewness y kurtosis) de una distribución normal (véase Lütkepohl, 1991). Según los estadísticos los residuos son ruido blanco y están normalmente distribuidos (véase anexo, pp. 118-119). 


\section{CUADRO 6}

Test de causalidad de Granger

\begin{tabular}{|c|c|c|c|}
\hline $\begin{array}{c}\text { Hipótesis nula } \\
\text { (periodo 1905-1955) }\end{array}$ & $\begin{array}{l}\text { Número } \\
\text { de rezagos }\end{array}$ & $\begin{array}{c}\text { Estadístico } \\
F\end{array}$ & $\begin{array}{c}\text { Valor de } \\
\text { probabilidad }\end{array}$ \\
\hline 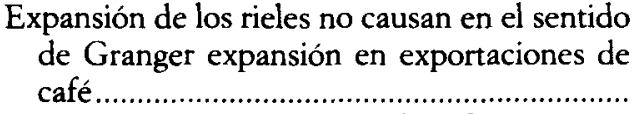 & 1 & 6.206 & 0,004 \\
\hline $\begin{array}{l}\text { Expansión en exportaciones de café no causan } \\
\text { en el sentido de Granger expansión de los } \\
\text { rieles }\end{array}$ & 1 & 4.040 & 0,025 \\
\hline
\end{tabular}

donde: $y_{t}$ es el log de las exportaciones de café durante el período t; $x_{t}$ es el log de la longitud de la red ferroviaria durante el período t; $\alpha_{i}$ es la constante; $A_{i j}$ son los polinomios del operador de rezagos $\mathrm{L}$, y $\mu_{1 t}, \mu_{2 t}$ son los términos del error, los cuales son ruido blanco.

La Gráfica 5 presenta los resultados de la función impulso-respuesta derivada de la estimación del modelo VAR. En este caso, esta función cuantifica el efecto de un choque inicial en la longitud de la red férrea sobre las exportaciones de café y viceversa ${ }^{39}$. En general, estas innovaciones

\section{GRÁFICA 5}

\section{Función Impulso-Respuesta}

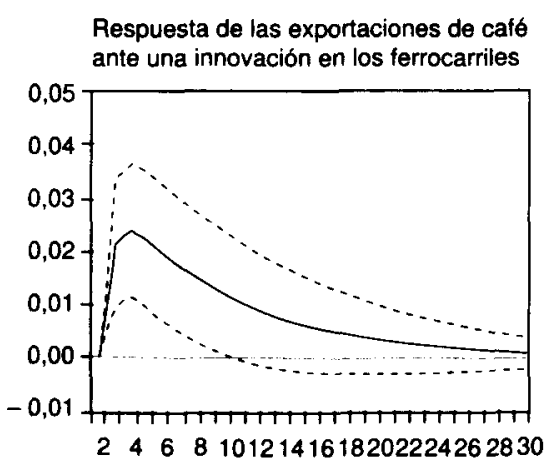

Años

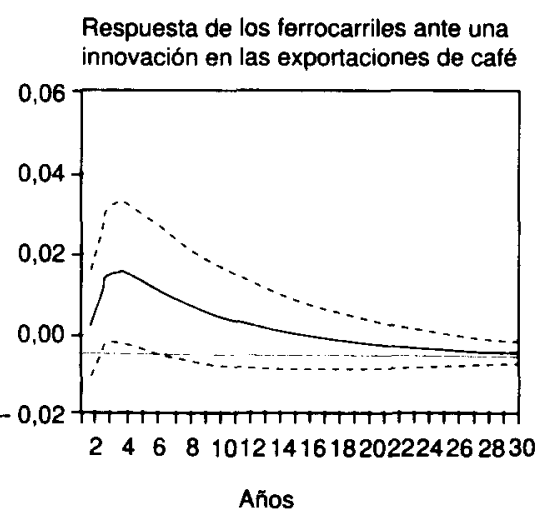

Años

${ }^{39}$ El problema de la identificación es importante en este tipo de estimación. Para 
son medidas en términos de una desviación estándar de la variable a la que se le proporciona el choque en el primer período.

El eje vertical de la gráfica mide la respuesta ante la innovación, el eje horizontal mide el tiempo que sigue a dicha innovación, y las líneas punteadas representan los intervalos de confianza. Como se observa, incrementos en la red férrea producen expansiones en las exportaciones de café. El efecto alcanza su máximo en el período cuatro y luego, dado la naturaleza estacionaria de la serie, el efecto empieza a desaparecer. De otra parte, un choque en las exportaciones de café afecta positivamente la longitud de la red férrea. Es decir, aumentos en las exportaciones de café inducen nuevas construcciones o expansiones de la red. $\mathrm{Al}$ año siguiente de la innovación la construcción de los ferrocarriles aumenta alcanzando su punto máximo a los cuatro años del choque; posteriormente, dado que la serie es estacionaria, el efecto en el tiempo desaparece.

Para facilitar la interpretación de los resultados es conveniente estandarizar la magnitud de la respuesta en términos de la desviación estándar del residuo. La homogeneización es de la siguiente manera: se divide la respuesta de cada variable por la desviación estándar del residual de su varianza. Por lo tanto, todas las respuestas se encuentran en fracciones de desviaciones estándar y se pueden interpretar como elasticidades. En este caso, la elasticidad máxima, en el cuarto período después del choque, de las exportaciones de café ante cambios en la red férrea es 0,18 . De otra parte, la elasticidad máxima de la red férrea ante cambios en las exportaciones de café es 0,14 . Como se observa, la respuesta es mayor en el caso de las exportaciones de café. Sin embargo, en ambos casos la magnitud de esta respuesta es relativamente baja, debido a que a lo sumo representa un quinto de la desviación estándar (Gráfica 6).

Una de las razones que pueden explicar estos resultados es que el sistema férreo no estaba integrado, ya que se extendieron pocos kilómetros de rieles y las líneas estaban físicamente separadas. Por lo tanto, aunque los ferrocarriles fomentaron y fueron importantes en las exportaciones de café, éstos fueron rápidamente reemplazados por las carreteras perdiendo los trenes importancia en el transporte de carga. El problema fue que los ferrocarriles en Colombia se construyeron relativamente tarde. El auge

ortogonalizar las innovaciones, se utiliza la descomposición de Choleski. El ordenamiento de las variables es: logaritmo de las exportaciones de café seguido por el logaritmo de la longitud de la red ferroviaria. Es de señalar que en estos resultados el orden de las variables no tiene un impacto cuantitativo sobre los resultados, debido a que la correlación contemporánea entre los errores es pequeña $(0,092)$. 


\section{GRÁFICA 6}

\section{Función Impulso-Respuesta Homogeneizada}

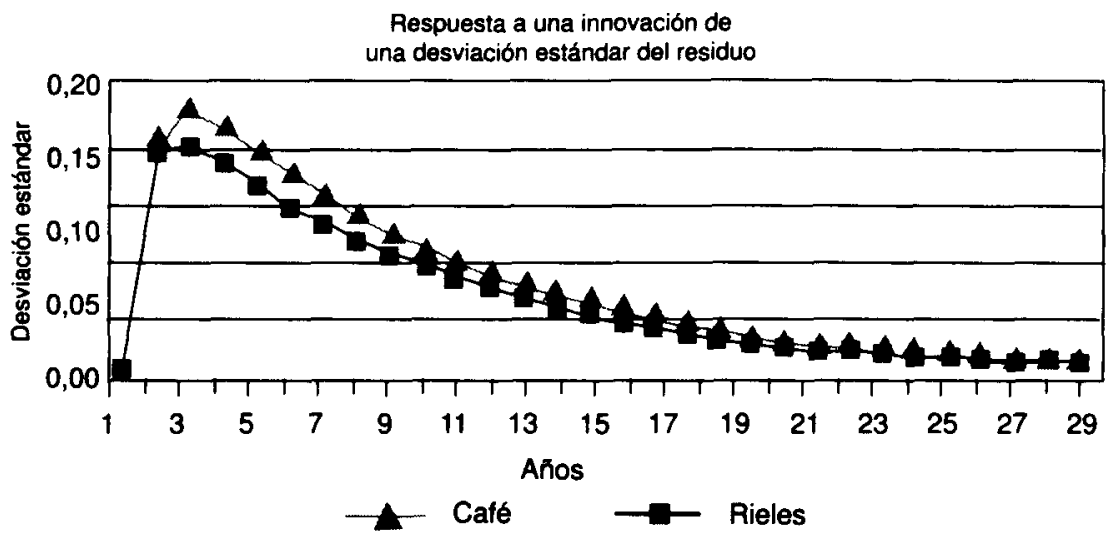

en la construcción de los ferrocarriles coincidió con la época en la cual el desarrollo del transporte automotor estaba tomando impulso y por esta razón éstos reemplazaron a los ferrocarriles en el transporte de carga, incluido el café. Las políticas de transporte en Colombia no permitieron la consolidación de un sistema en el cual tuvieran cabida los diferentes medios de transporte. A lo largo del tiempo, estas políticas llevaron al fortalecimiento del transporte por carreteras en detrimento del transporte férreo y fluvial.

Si se compara con la experiencia de otros países latinoamericanos se encuentra que el caso de las exportaciones de café en Brasil fue similar al de Colombia. Según W. Summerhill (1995), los cultivadores de café en Brasil obtuvieron en un principio grandes beneficios con la disminución del costo de transporte generado por la construcción de los ferrocarriles; sin embargo, estos beneficios fueron decayendo rápidamente con el paso del tiempo. Por el contrario, en México los ferrocarriles jugaron un papel fundamental en el fomento de las exportaciones. De acuerdo con J. Coatsworth (1981), más de la mitad del ahorro social del transporte de carga de los ferrocarriles mexicanos fue atribuido al sector exportador. 


\section{DESARROLLO EN LA INFRAESTRUCTURA DE TRANSPORTE Y SU EFECTO SOBRE LA INTEGRACIÓN DEL MERCADO: CONVERGENCIA DE LOS PRECIOS DE PRODUCTOS AGRÍCOLAS ENTRE REGIONES}

El desarrollo en infraestructura reduce el costo de transporte de un bien y, por lo tanto, su precio en el mercado. De esta forma, se conectan mercados distantes y se disminuye la brecha de precios de un mismo bien entre regiones. Esta sección busca verificar esta hipótesis para los precios agrícolas en Colombia utilizando dos medidas: i) la evolución del coeficiente de variación, y ii) el cálculo de coeficientes de convergencia. Con este fin, se ensamblan series de precios anuales para seis productos agrícolas en las doce ciudades más grandes del país para el período 1928-1990. Los bienes de la muestra son: patata, arroz, maíz, azúcar, sal y panela, siendo estos bienes componentes típicos de una canasta de consumo en Colombia, y las ciudades son Bogotá, Barranquilla, Bucaramanga, Cali, Manizales, Medellin, Pasto, Cartagena, Cúcuta, Neiva, Pereira y Villavicencio, las cuales representan diferentes regiones del país.

\subsection{Evolución del coeficiente de variación}

Una medida sencilla para examinar la dispersión de precios entre regiones es el coeficiente de variación. Como se observa en la Gráfica 7, la dispersión inter-regional de los precios antes de los años treinta era considerable. Esta dispersión fue el resultado de las deficiencias en la infraestructura de transporte, debido en parte a barreras geográficas, que resultaron en altos costos de transporte y aislamiento de las regiones. Durante la década de los treinta este coeficiente, para todos los bienes, se redujo de forma importante. Por ejemplo, a finales de 1930 la dispersión regional de los precios fue considerablemente menor que en la década anterior. De hecho, los coeficientes de variación de algunos de los precios agrícolas en 1938 son tres veces más pequeños que en 1928. La caída en el coeficiente puede estar asociada con el desarrollo del transporte, lo cual redujo las tarifas e interconectó algunos mercados. Sin embargo, se debe tener en cuenta que este período se caracterizó por la depresión y la Segunda Guerra Mundial. Después de los años cuarenta se siguen presentando disminuciones en el coeficiente de variación aunque a tasas mucho menores a las presentadas en la década de los treinta. 


\section{GRÁFICA 7}

Evolución del coeficiente de variación (C.V.) para el precio de algunos bienes en Colombia

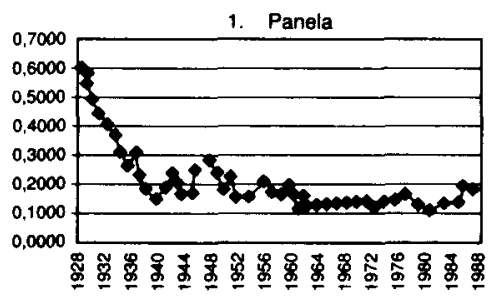

$\longrightarrow$ C. V. panela

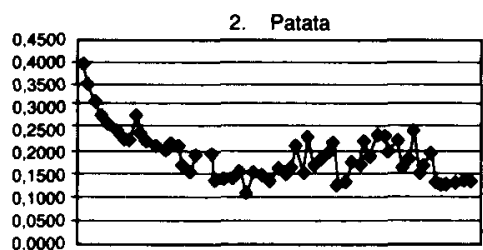



$\sim$ C. V. patatas

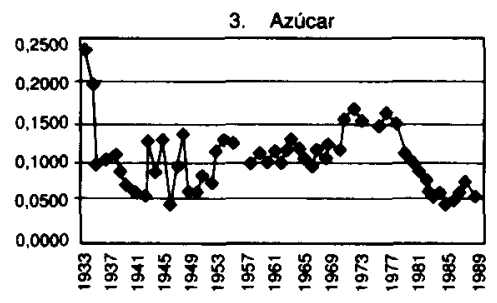

$\rightarrow$ C. V. azúcar

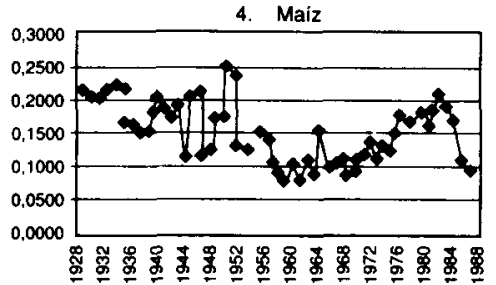

$\multimap$ C. V. maíz

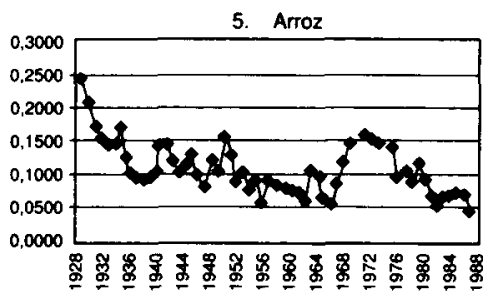

$\rightarrow$ C. V. arroz

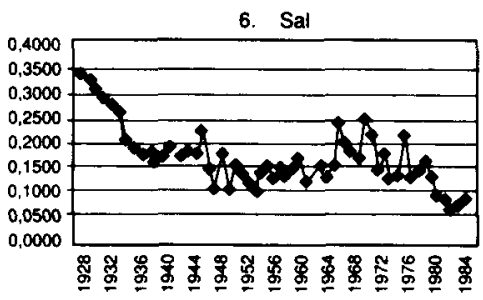

C. V. sal

\subsection{Convergencia entre pares de ciudades}

Estimar la tasa de convergencia entre pares de ciudades, permite examinar si existe igualación de precios entre regiones. Para calcular la tasa de convergencia, se parte del supuesto que la relación de precios entre la región A y B puede ser descrita como $P_{B}=(1+c) P_{A}$, donde $c$ es el costo de transporte, y $P_{A}\left\langle P_{B}\right.$. Por lo tanto, $P_{B} / P_{A}$ tiende a uno cuando el costo de transporte tiende a cero. Esta relación se estima 
en términos de una especificación lineal logarítmica de la forma: $\ln \left(P_{B} / P_{A}\right)_{i t}=\alpha_{i}+\beta t+\varepsilon_{i t}$. Si $\beta<0$ la serie converge, si $\beta>0$ la serie diverge $^{40}$. Para estimar esta relación es necesario construir razones de precios entre ciudades para cada bien, en donde la razón inicial debe ser mayor que uno; de esta forma, estas razones deben tender a uno en caso de convergencia. En el presente artículo, se examina la convergencia de los precios de seis bienes agrícolas entre siete ciudades colombianas para el período 1928-1990 y los sub-períodos 1928-1950 y 1950-1990.

Como se observa en el Cuadro 7, durante 1928-1950 las tasas de convergencia son en general mayores que las de 1950-1990. Esto se debe a que durante el primer período las dispersiones iniciales entre precios eran más grandes y, por lo tanto, la convergencia entre ellos tiende a ser más rápida. Este resultado concuerda con la evolución del coeficiente de variación descrita anteriormente. En particular, si se analiza todo el período (1928-1990 $)^{41}$ se encuentra que en el caso de la patata, ocho razones de precios convergen, dos razones divergen, y el coeficiente de las restantes once no es estadísticamente significativo. Sin embargo, la magnitud de la tasa de convergencia es moderada, su rango varía entre 0,0075 y 0,002 . Si se toma la tasa de convergencia más alta (Cali/Manizales), la razón de precios entre estas dos ciudades converge a una tasa de 0,75 por 100 anual y tomaría cerca de noventa y dos años para cerrar la mitad de la brecha del precio entre estas dos ciudades.

De otro lado, en el caso de la panela, doce razones de precios convergen, dos razones divergen, y siete no son estadísticamente diferentes de cero. En general, la tasa de convergencia del precio de la panela es más alta que la de la patata. Para el precio del arroz se encuentra convergencia para doce razones de precios, aunque la convergencia es menor que en el caso anterior. Para el maíz, once razones de precios convergen; para la sal, diez cocientes tienden a uno, y, por último, el precio del azúcar presenta las menores tasas de convergencia. Los resultados sugieren que entre las grandes ciudades colombianas ha sido mayor la integración de los mercados en el largo plazo, aunque ésta se ha realizado a un ritmo moderado. La deficiencia existente en la infraestructura de transporte puede ser una de las causas para que la convergencia de los precios en las demás regiones sea aún lenta.

40 Fsta metodología es utilizada por M. Slaughter (1995), quien estima la conEstados Unidos.

4 Por motivos de disponibilidad de cifras para la panela y el azúcar el período se restringe a 1933-1990. 


\section{CUADRO 7}

Convergencia de precios entre ciudades. Producto: Arroz

\begin{tabular}{|c|c|c|c|c|c|c|}
\hline \multirow{2}{*}{$\begin{array}{c}\text { Razones de precios } \\
\text { entre ciudades } \\
\text { In }\left(P_{B} / P_{A}\right)\end{array}$} & \multicolumn{2}{|c|}{$1928-1950$} & \multicolumn{2}{|c|}{$1950-1990$} & \multicolumn{2}{|c|}{$1928-1990$} \\
\hline & $\begin{array}{c}\text { Tasa de } \\
\text { convergencia }(\beta)\end{array}$ & $R^{2}$ & $\begin{array}{c}\text { Tasa de } \\
\text { convergencia }(\beta)\end{array}$ & $R^{2}$ & $\begin{array}{c}\text { Tasa de } \\
\text { convergencia }(\beta)\end{array}$ & $R^{2}$ \\
\hline Bogotá/Barranquilla ........... & $\begin{array}{c}-0,0376 \\
(0,004)^{k \star *}\end{array}$ & 0,813 & $\begin{array}{c}-0,0014 \\
(0,001)\end{array}$ & 0,052 & $\begin{array}{c}-0,0067 \\
(0,001)^{* * *}\end{array}$ & 0,357 \\
\hline Bucaramanga/Bogotá ......... & $\begin{array}{l}0,0048 \\
(0,004)\end{array}$ & 0,065 & $\begin{array}{c}0,0037 \\
(0,002)^{\star}\end{array}$ & 0,099 & $\begin{array}{l}-0,0011 \\
(0,001)\end{array}$ & 0,023 \\
\hline Bogotá/Cali & $\begin{array}{c}-0,0194 \\
(0,001)^{\star * *}\end{array}$ & 0,944 & $\begin{array}{l}0,0016 \\
(0,001)\end{array}$ & 0,088 & $\begin{array}{c}-0,0052 \\
(0,001)\end{array}$ & 0,451 \\
\hline Bogotá/Manizales.. & $\begin{array}{c}-0,0242 \\
(0,002)^{\star \star \star}\end{array}$ & 0,841 & $\begin{array}{c}-0,0037 \\
(0,001)^{* * *}\end{array}$ & 0,386 & $\begin{array}{c}-0,0030 \\
(0,001)^{* * *}\end{array}$ & 0,168 \\
\hline Bogotá/Medellin..... & $\begin{array}{c}-0,0213 \\
(0,004)^{\star \star *}\end{array}$ & 0,590 & $\begin{array}{r}-0,0020 \\
(0,001)^{\star *}\end{array}$ & 0,297 & $\begin{array}{c}-0,0021 \\
(0,001)^{* * *}\end{array}$ & 0,101 \\
\hline Bogotá/Pasto...... & $\begin{array}{c}-0,0097 \\
(0,0028)^{* * *}\end{array}$ & 0,353 & $\begin{array}{c}-0,0026 \\
(0,001)\end{array}$ & 0,107 & $\begin{array}{c}-0,0002 \\
(0,001)\end{array}$ & 0,001 \\
\hline Bucaramanga/Barranquilla. & $\begin{array}{c}-0,0328 \\
(0,006)^{\star * *}\end{array}$ & 0,583 & $\begin{array}{c}-0,0051 \\
(0,001)^{* \star *}\end{array}$ & 0,245 & $\begin{array}{c}-0,0077 \\
(0,001)^{k \star *}\end{array}$ & 0,396 \\
\hline Cali/Barranquilla .... & $\begin{array}{c}-0,0182 \\
(0,004)^{\star \star \star}\end{array}$ & 0,488 & $\begin{array}{c}-0,0024 \\
(0,001)\end{array}$ & 0,064 & $\begin{array}{c}-0,0015 \\
(0,001)\end{array}$ & 0,037 \\
\hline Manizales/Barranquilla....... & $\begin{array}{c}-0,0166 \\
(0,004)^{k \star *}\end{array}$ & 0,490 & $\begin{array}{c}-0,0051 \\
(0,002)^{k \star *}\end{array}$ & 0,226 & $\begin{array}{c}-0,0037 \\
(0,001)^{* * *}\end{array}$ & 0,230 \\
\hline Medellin/Barranquilla ........ & $\begin{array}{c}-0,0192 \\
(0,004)^{\star \star \star}\end{array}$ & 0,516 & $\begin{array}{c}-0,0035 \\
(0,001)^{* * *}\end{array}$ & 0,185 & $\begin{array}{c}-0,0045 \\
(0,001)^{\star * *}\end{array}$ & 0,347 \\
\hline Pasto/Barranquilla. & $\begin{array}{c}-0,0307 \\
(0,004)^{* 4 *}\end{array}$ & 0,771 & $\begin{array}{c}-0,0011 \\
(0,001)\end{array}$ & 0,018 & $\begin{array}{c}-0,0064 \\
(0,011)\end{array}$ & 0,030 \\
\hline Bucaramanga/Cali. & $\begin{array}{c}-0,0145 \\
(0,004)^{\star * *}\end{array}$ & 0,424 & $\begin{array}{c}0,0021 \\
(0,002)\end{array}$ & 0,026 & $\begin{array}{c}-0,0063 \\
(0,001)^{* * *}\end{array}$ & 0,374 \\
\hline Bucaramanga/Manizales .... & $\begin{array}{c}-0,0201 \\
(0,005)^{\star \star \star}\end{array}$ & 0,447 & $\begin{array}{l}0,0001 \\
(0,002)\end{array}$ & 0,001 & $\begin{array}{c}-0,0041 \\
(0,001)^{\star \star \star}\end{array}$ & 0,165 \\
\hline Bucaramanga/Medellín ...... & $\begin{array}{c}-0,0176 \\
(0,003)^{* * *}\end{array}$ & 0,565 & $\begin{array}{l}0,0016 \\
(0,002)\end{array}$ & 0,021 & $\begin{array}{c}-0,0032 \\
(0,001)^{\star * *}\end{array}$ & 0,161 \\
\hline Bucaramanga/Pasto............. & $\begin{array}{c}-0,0060 \\
(0,005)\end{array}$ & 0,006 & $\begin{array}{c}-0,0063 \\
(0,001)^{\star \star \star}\end{array}$ & 0,351 & $\begin{array}{c}-0,0013 \\
(0,001)\end{array}$ & 0,031 \\
\hline Manizales/Cali. & $\begin{array}{c}0,0056 \\
(0,003)^{\star}\end{array}$ & 0,207 & $\begin{array}{c}-0,0021 \\
(0,001)^{* * *}\end{array}$ & 0,260 & $\begin{array}{c}-0,0022 \\
(0,000)^{* * *}\end{array}$ & 0,308 \\
\hline Medellin/Cali.. & $\begin{array}{c}0,0031 \\
(0,004)\end{array}$ & 0,032 & $\begin{array}{c}-0,0004 \\
(0,001)\end{array}$ & 0,014 & $\begin{array}{c}-0,0031 \\
(0,001)^{* * *}\end{array}$ & 0,309 \\
\hline Pasto/Cali. & $\begin{array}{l}-0,0084 \\
(0,003)^{* 4}\end{array}$ & 0,246 & $\begin{array}{c}-0,0042 \\
(0,001)\end{array}$ & 0,188 & $\begin{array}{c}-0,0050 \\
(0,001)^{* * *}\end{array}$ & 0,288 \\
\hline Medellin/Manizales . & $\begin{array}{c}-0,0024 \\
(0,005)\end{array}$ & 0,013 & $\begin{array}{c}-0,0016 \\
(0,001)^{* \times 4}\end{array}$ & 0,202 & $\begin{array}{l}-0,0010 \\
(0,0006)\end{array}$ & 0,027 \\
\hline Pasto/Manizales ....... & $\begin{array}{c}-0,0141 \\
(0,002)^{\star \star \star}\end{array}$ & 0,600 & $\begin{array}{c}-0,0063 \\
(0,001)\end{array}$ & 0,379 & $\begin{array}{l}-0,0020 \\
(0,0012)\end{array}$ & 0,098 \\
\hline Medellin/Pasto.. & $\begin{array}{c}0,0115 \\
(0,004)^{\star \star}\end{array}$ & 0,271 & $\begin{array}{r}-0,0046 \\
(0,001)^{\star k *}\end{array}$ & 0,316 & $\begin{array}{c}0,0020 \\
(0,001)^{k \star}\end{array}$ & 0,074 \\
\hline
\end{tabular}

Notas: Desviaciones standard en paréntesis, ${ }^{*}$ significativo al 10 por $100,{ }^{* *}$ significativo al 5 por $100, * * *$ significativo al 1 por 100 . 
CUADRO 7 (Cont.)

Convergencia de precios entre ciudades. Producto: Maíz

\begin{tabular}{|c|c|c|c|c|c|c|}
\hline \multirow{2}{*}{$\begin{array}{l}\text { Razones de precios } \\
\text { entre ciudades } \\
\ln \left(P_{B} / P_{A}\right)\end{array}$} & \multicolumn{2}{|c|}{$1928-1950^{2}$} & \multicolumn{2}{|l|}{$1950-1990$} & \multicolumn{2}{|c|}{$1928.1990^{2}$} \\
\hline & $\begin{array}{c}\text { Tasa de } \\
\text { convergencia }(\beta)\end{array}$ & $R^{2}$ & $\begin{array}{c}\text { Tasa de } \\
\text { convergencia }(\beta)\end{array}$ & $R^{2}$ & $\begin{array}{c}\text { Tasa de } \\
\text { convergencia }(\beta)\end{array}$ & $R^{2}$ \\
\hline ogotá/Barranquilla ......... & & 0,003 & $\begin{array}{c}0,0012 \\
(0,003)\end{array}$ & 0,006 & $\begin{array}{l}-0,0018 \\
(0,001)\end{array}$ & 0,034 \\
\hline Bogotá/Bucaramanga . & $\begin{array}{l}-0,0028 \\
(0,0079)\end{array}$ & 0,008 & $\begin{array}{c}-0,0110 \\
(0,002)^{\star * *}\end{array}$ & 0,461 & $\begin{array}{c}0,0047 \\
(0,001)^{\star \star \star}\end{array}$ & 0,221 \\
\hline Cali/Bogotá .. & $\begin{array}{l}-0,0093 \\
(0,004)^{* \star}\end{array}$ & 0,174 & $\begin{array}{c}-0,0154 \\
(0,002)^{* * *}\end{array}$ & 0,603 & $\begin{array}{c}-0,0062 \\
(0,001)^{\star \star \star}\end{array}$ & 0,287 \\
\hline Manizales/Bogotá. & $\begin{array}{l}-0,0078 \\
(0,007)\end{array}$ & 0,059 & $\begin{array}{c}-0,0122 \\
(0,002)^{\star \star *}\end{array}$ & 0,496 & $\begin{array}{c}-0,0080 \\
(0,000)^{\star \star \star}\end{array}$ & 0,421 \\
\hline 3ogotá/Medellin ${ }^{1}$ & $\begin{array}{c}-0,0159 \\
(0,004)^{* * *}\end{array}$ & 0,393 & $\begin{array}{c}-0,0108 \\
(0,002)^{\star * \star}\end{array}$ & 0,458 & $\begin{array}{l}0,0037 \\
(0,002)\end{array}$ & 0,126 \\
\hline Bogotá/Pas & $\begin{array}{l}-0,0123 \\
(0,006)^{* * *}\end{array}$ & 0,235 & $\begin{array}{c}0,0091 \\
(0,002)^{\star * *}\end{array}$ & 0,415 & $\begin{array}{c}0,0045 \\
(0,001)^{\star \star \star \star}\end{array}$ & 0,194 \\
\hline Bucarama & $\begin{array}{l}0,0047 \\
(0,008)\end{array}$ & 0,019 & $\begin{array}{c}-0,0090 \\
(0,001)^{* * *}\end{array}$ & 0,543 & $\begin{array}{c}-0,0105 \\
(0,001)^{\star \star *}\end{array}$ & 0,692 \\
\hline Cali/Barra & $\begin{array}{l}-0,0069 \\
(0,009)\end{array}$ & 0,039 & $\begin{array}{c}-0,0125 \\
(0,001)^{* * *}\end{array}$ & 0,669 & $\begin{array}{c}-0,0090 \\
(0,001)^{\star \star *}\end{array}$ & 0,507 \\
\hline Mani: & $\begin{array}{l}0,0056 \\
(0,008)\end{array}$ & 0,028 & $\begin{array}{c}-0,0110 \\
(0,002)^{* * *}\end{array}$ & 0,529 & $\begin{array}{c}-0,0104 \\
(0,001)^{\star * *}\end{array}$ & 0,617 \\
\hline Barr & $\begin{array}{c}-0,0286 \\
(0,006)^{\star \star \star}\end{array}$ & 0,493 & $\begin{array}{c}-0,0095 \\
(0,002)^{* * *}\end{array}$ & 0,504 & $\begin{array}{r}-0 \\
(0,00 \\
-0\end{array}$ & 0,761 \\
\hline asto/l & $\begin{array}{l}0,0040 \\
(0,009)\end{array}$ & 0,015 & $\begin{array}{c}-0,0095 \\
(0,002)^{\star \star \star}\end{array}$ & 0,410 & $\begin{array}{r}-0, \\
(0,00 \\
-0\end{array}$ & \\
\hline Cali/Bucaram & $\begin{array}{l}-0,0117 \\
(0,006)^{*}\end{array}$ & 0,155 & $\begin{array}{c}-0,0042 \\
(0,001)^{* \star *}\end{array}$ & 0,245 & $\begin{aligned}-0,6 \\
10,0 \\
-0,\end{aligned}$ & 0,034 \\
\hline Manizales .... & $\begin{array}{c}-0,0009 \\
(0,010)\end{array}$ & 0,001 & $\begin{array}{l}-0,0018 \\
(0,002)\end{array}$ & 0,037 & $\begin{aligned}-0,6 \\
10,0 \\
-0,\end{aligned}$ & 0,027 \\
\hline Bucat & $\begin{array}{l}-0,0007 \\
(0,005)\end{array}$ & 0,001 & $\begin{array}{l}-0,0002 \\
(0,001)\end{array}$ & 0,000 & $\begin{array}{l}-0,0 \\
(0,0 \\
-0,0\end{array}$ & 0005 \\
\hline $\mathrm{Bu}$ & $\begin{array}{l}-0,0094 \\
(0,008)\end{array}$ & 0,071 & $\begin{array}{l}-0,0003 \\
(0,002)\end{array}$ & 0,001 & $\begin{array}{l}-0,0006 \\
(0,001) \\
-0,0014\end{array}$ & $0,00\rangle$ \\
\hline Maniz: & $\begin{array}{l}0,0014 \\
(0,006)\end{array}$ & 0,003 & $\begin{array}{l}0,0020 \\
(0,001)\end{array}$ & 0,091 & & 0,087 \\
\hline Cali/Mec & $\begin{array}{c}-0,0253 \\
(0,005)^{\star * *}\end{array}$ & 0,597 & $\begin{array}{c}-0,0042 \\
(0,001)^{\star \star \star}\end{array}$ & 0,312 & $\begin{array}{l}(0,001)^{\star *} \\
-0,0021\end{array}$ & 0,054 \\
\hline Cali/Paste & $\begin{array}{l}-0,0211 \\
(0,007)^{* * *}\end{array}$ & 0,334 & $\begin{array}{c}-0,0047 \\
(0,002)^{\star \star \star}\end{array}$ & 0,227 & $\begin{array}{l}(0,001)^{*} \\
-0,0040\end{array}$ & 0,142 \\
\hline Manizales/Medellín. & $\begin{array}{c}-0,0238 \\
(0,007)^{\star \star}\end{array}$ & 0,317 & $\begin{array}{l}-0,0018 \\
(0,001)^{\star *}\end{array}$ & 0,061 & $\begin{array}{r}(0, \infty) \\
-0\end{array}$ & 0,060 \\
\hline Manizales/Pasto. & $\begin{array}{c}-0,0084 \\
(0,010)\end{array}$ & 0,045 & $\begin{array}{c}-0,0026 \\
(0,002)\end{array}$ & 0,000 & $\begin{array}{l}10, \\
-0,\end{array}$ & 0,074 \\
\hline Medellín & $\begin{array}{c}-0,0119 \\
(0,005)^{\star * \star}\end{array}$ & 0,225 & $\begin{array}{c}-0,0002 \\
(0,002)\end{array}$ & 0,000 & $(0,001)^{\star *}$ & \\
\hline
\end{tabular}

Notas: Desviaciones standard en paréntesis, * significativo al 10 por $100,{ }^{* \star}$ significativo al 5 por $100,{ }^{* * *}$ significativo al 1 por 100 .

${ }^{1}$ Para el periodo 1950-1990, la razón de precios es Medellín/Bogotá para el maíz.

2 Los datos para el maíz en Pasto sólo se encuentran disponibles a partir de 1934. 
CUADRO 7 (Cont.)

Convergencia de precios entre ciudades. Producto: Patata

\begin{tabular}{|c|c|c|c|c|c|c|}
\hline \multirow{2}{*}{$\begin{array}{l}\text { Razones de precios } \\
\text { entre ciudades } \\
\text { In }\left(P_{B} P_{A}\right)\end{array}$} & \multicolumn{2}{|c|}{$1928-1950$} & \multicolumn{2}{|c|}{$1950-1990$} & \multicolumn{2}{|c|}{$1928-1990$} \\
\hline & $\begin{array}{c}\text { Tasa de } \\
\text { convergencia ( }(\beta)\end{array}$ & $R^{2}$ & $\begin{array}{c}\text { Tasa de } \\
\text { convergencia ( } \beta)\end{array}$ & $R^{2}$ & $\begin{array}{c}\text { Tasa de } \\
\text { convergencia (B) }\end{array}$ & $R^{2}$ \\
\hline Barranquilla/Bogotá ................ & $\begin{array}{c}-0,0049 \\
(0,003)\end{array}$ & 0,074 & $\begin{array}{c}-0,0113 \\
(0,001)^{k * x}\end{array}$ & 0,804 & $\begin{array}{c}-0,0045 \\
(0,001)^{* * *}\end{array}$ & 0,339 \\
\hline Bucaramanga/Bogotá & $\begin{array}{c}-0,0122 \\
(0,006)^{* *}\end{array}$ & 0,269 & $\begin{array}{c}-0,0041 \\
(0,001)^{* * *}\end{array}$ & 0,237 & $\begin{array}{c}-0,0020 \\
(0,001)^{\dot{*} * *}\end{array}$ & 0,094 \\
\hline Cali/Bogotá . & $\begin{array}{c}-0,0236 \\
(0,006)^{* * * k}\end{array}$ & 0,402 & $\begin{array}{c}-0,0079 \\
(0,002)^{* k *}\end{array}$ & 0,288 & $\begin{array}{c}-0,0067 \\
(0,001)^{* * * *}\end{array}$ & 0,330 \\
\hline Manizales/Bogotá..... & $\begin{array}{l}-0,0106 \\
(0,008)\end{array}$ & 0,081 & $\begin{array}{c}-0,0053 \\
(0,001)^{\star * *}\end{array}$ & 0,335 & $\begin{array}{l}-0,0014 \\
(0,001)\end{array}$ & 0,023 \\
\hline Medellín/Bogotá.... & $\begin{array}{r}0,0058 \\
(0,004)\end{array}$ & 0,089 & $\begin{array}{r}-0,0024 \\
(0,002)\end{array}$ & 0,056 & $\begin{array}{l}0,0005 \\
(0,001)\end{array}$ & 0,007 \\
\hline 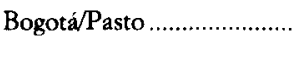 & $\begin{array}{c}-0,0169 \\
(0,004)^{\star \star * *}\end{array}$ & 0,446 & $\begin{array}{c}0,0099 \\
(0,002)^{\star * \star}\end{array}$ & 0,434 & $\begin{array}{r}0,0007 \\
(0,001)\end{array}$ & 0,006 \\
\hline Bucaramanga/Barranquilla. & $\begin{array}{r}-0,0089 \\
(0,005)\end{array}$ & 0,118 & $\begin{array}{c}-0,0072 \\
(0,001)^{\star \star}\end{array}$ & 0,481 & $\begin{array}{c}0,0022 \\
(0,001)^{*}\end{array}$ & 0,081 \\
\hline Cali/Barranquilla ....................... & $\begin{array}{r}0,0008 \\
(0,005)\end{array}$ & 0,002 & $\begin{array}{l}-0,0032 \\
(0,002)^{*}\end{array}$ & 0,069 & $\begin{array}{r}-0,0005 \\
(0,001)\end{array}$ & 0,004 \\
\hline Manizales/Barranquilla $\ldots . . . . .$. & $\begin{array}{r}0,0163 \\
(0,009)\end{array}$ & 0,128 & $\begin{array}{c}-0,0059 \\
(0,001)^{* * *}\end{array}$ & 0,296 & $\begin{array}{c}0,0028 \\
(0,001)^{\star \star}\end{array}$ & 0,081 \\
\hline Barranquilla/Medellín ......... & $\begin{array}{c}-0,0113 \\
(0,005)^{\text {** }}\end{array}$ & 0,203 & $\begin{array}{c}-0,0080 \\
(0,002)^{* * *}\end{array}$ & 0,347 & $\begin{array}{c}-0,0034 \\
(0,001)^{* * *}\end{array}$ & 0,138 \\
\hline Barranquilla/Pasto ................... & $\begin{array}{c}-0,0327 \\
(0,008)^{k \star *}\end{array}$ & 0,493 & $\begin{array}{l}0,0014 \\
(0,002)\end{array}$ & 0,013 & $\begin{array}{r}-0,0017 \\
(0,002)\end{array}$ & 0,022 \\
\hline Cali/Bucaramanga ................... & $\begin{array}{l}-0,0081 \\
(0,006)\end{array}$ & 0,108 & $\begin{array}{c}-0,0040 \\
(0,002)^{* * *}\end{array}$ & 0,112 & $\begin{array}{c}-0,0050 \\
(0,001)^{* * *}\end{array}$ & 0,292 \\
\hline Bucaramanga/Manizales .... & $\begin{array}{r}-0,0087 \\
(0,006)\end{array}$ & 0,105 & $\begin{array}{c}-0,0012 \\
(0,001)\end{array}$ & 0,022 & $\begin{array}{l}-0,0006 \\
(0,001)\end{array}$ & 0,010 \\
\hline Bucaramanga/Medellín ....... & $\begin{array}{l}-0,0050 \\
(0,008)\end{array}$ & 0,019 & $\begin{array}{l}0,0007 \\
(0,002)\end{array}$ & 0,004 & $\begin{array}{l}0,0008 \\
(0,001)\end{array}$ & 0,009 \\
\hline Bucaramanga/Pasto ................ & $\begin{array}{c}-0,0212 \\
(0,009)^{\star *}\end{array}$ & 0,241 & $\begin{array}{c}0,0032 \\
(0,002)\end{array}$ & 0,049 & $\begin{array}{r}-0,0010 \\
(0,002)\end{array}$ & 0,006 \\
\hline Cali/Manizales ........................... & $\begin{array}{c}-0,0168 \\
(0,008)^{* *}\end{array}$ & 0,235 & $\begin{array}{c}-0,0043 \\
(0,002)^{* * *}\end{array}$ & 0,174 & $\begin{array}{c}-0,0075 \\
(0,001)^{* k * k}\end{array}$ & 0,593 \\
\hline 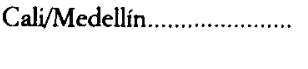 & $\begin{array}{c}0,0301 \\
(0,007)^{\star * *}\end{array}$ & 0,492 & $\begin{array}{c}-0,0048 \\
(0,003)\end{array}$ & 0,062 & $\begin{array}{c}-0,0075 \\
(0,002)^{* k * k}\end{array}$ & 0,255 \\
\hline Cali/Pasto & $\begin{array}{c}-0,0294 \\
(0,011)^{\star * *}\end{array}$ & 0,292 & $\begin{array}{c}0,0022 \\
(0,0016)\end{array}$ & 0,054 & $\begin{array}{c}-0,0008 \\
(0,002)\end{array}$ & 0,006 \\
\hline Manizales/Medellín .............. & $\begin{array}{l}-0,0170 \\
(0,009)^{\star}\end{array}$ & 0,155 & $\begin{array}{r}0,0020 \\
(0,002)\end{array}$ & 0,024 & $\begin{array}{c}-0,0035 \\
(0,002)^{\star \star}\end{array}$ & 0,089 \\
\hline Manizales/Pasto ....................... & $\begin{array}{r}-0,0125 \\
(0,014)\end{array}$ & 0,048 & $\begin{array}{c}0,0074 \\
(0,002)^{\star * *}\end{array}$ & 0,335 & $\begin{array}{r}-0,0007 \\
(0,001)\end{array}$ & 0,004 \\
\hline Medellín/Pasto ......................... & $\begin{array}{c}-0,0014 \\
(0,005)^{\star \star}\end{array}$ & 0,174 & $\begin{array}{c}0,0052 \\
(0,003)\end{array}$ & 0,067 & $\begin{array}{r}0,0017 \\
(0,002)\end{array}$ & 0,020 \\
\hline
\end{tabular}

Notas: Desviaciones standard en paréntesis, * significativo al 10 por $100,{ }^{* *}$ significativo al 5 por $100,{ }^{\star * *}$ significativo al 1 por 100 . 
CUADRO 7 (Cont.)

Convergencia de precios entre ciudades. Producto: Panela

\begin{tabular}{|c|c|c|c|c|c|c|}
\hline \multirow{2}{*}{$\begin{array}{l}\text { Razones de precios } \\
\text { entre ciudades } \\
\text { In }\left(P_{B} P_{A}\right)\end{array}$} & \multicolumn{2}{|l|}{$1928-1950$} & \multicolumn{2}{|c|}{$1950-1990$} & \multicolumn{2}{|l|}{$1928-1990$} \\
\hline & $\begin{array}{c}\text { Tasa de } \\
\text { convergencia }(B)\end{array}$ & $R^{2}$ & $\begin{array}{c}\text { Tasa de } \\
\text { convergencia }(\beta)\end{array}$ & $R^{2}$ & $\begin{array}{c}\text { Tasa de } \\
\text { comvergencia }(\beta)\end{array}$ & $R^{2}$ \\
\hline Barranquilla/B & $\begin{array}{r}0,0018 \\
(0,012)\end{array}$ & 0,002 & $\begin{array}{c}0,0085 \\
(0,002)^{\star \star \star}\end{array}$ & 0,412 & $\begin{array}{c}-0,0001 \\
(0,002)\end{array}$ & 0,000 \\
\hline Bogotá/Bucaran & $\begin{array}{c}-0,0369 \\
(0,006)^{\star \star \star}\end{array}$ & 0,683 & $\begin{array}{c}-0,0085 \\
(0,001)^{\star \star \star}\end{array}$ & 0,463 & $\begin{array}{c}-0,0162 \\
(0,001)^{\star * \star}\end{array}$ & 0,765 \\
\hline Bogotá/Cali . & $\begin{array}{c}-0,0158 \\
(0,005)^{\star \star \star}\end{array}$ & 0,353 & $\begin{array}{c}-0,0200 \\
(0,002)^{\star \star \star \star}\end{array}$ & 0,801 & $\begin{array}{c}-0,0152 \\
(0,001)^{\star * \star}\end{array}$ & 0,781 \\
\hline Maniz & $\begin{array}{l}-0,0090 \\
(0,005)^{\star}\end{array}$ & 0,170 & $\begin{array}{c}0,0123 \\
(0,002)^{\star \star \star}\end{array}$ & 0,549 & $\begin{array}{c}0,0053 \\
(0,001)^{\star \star \star}\end{array}$ & 0,281 \\
\hline Bogotá/M & $\begin{array}{l}-0,0138 \\
(0,008)^{\star}\end{array}$ & 0,171 & $\begin{array}{c}-0,0104 \\
(0,002)^{\star \star \star}\end{array}$ & 0,447 & $\begin{array}{c}-0,0100 \\
(0,001)^{\star \star \star *}\end{array}$ & 0,627 \\
\hline Bogotá/Pasto ${ }^{1}$.. & $\begin{array}{c}-0,0681 \\
(0,013)^{\star \star \star}\end{array}$ & 0,645 & $\begin{array}{c}0,0048 \\
(0,003)\end{array}$ & 0,051 & $\begin{array}{l}-0,0021 \\
(0,002)\end{array}$ & 0,013 \\
\hline Barranqui & $\begin{array}{c}-0,0314 \\
(0,009)^{\star \star \star}\end{array}$ & 0,493 & $\begin{array}{c}-0,0004 \\
(0,001)\end{array}$ & 0,003 & $\begin{array}{c}-0,0097 \\
(0,002)^{\star \star \star}\end{array}$ & 0,452 \\
\hline Barranquilla/Cali . & $\begin{array}{r}0,0086 \\
(0,011)\end{array}$ & 0,039 & $\begin{array}{c}-0,0109 \\
(0,001)^{\star \star \star}\end{array}$ & 0,764 & $\begin{array}{c}-0,0102 \\
(0,001)^{\star \star *}\end{array}$ & 0,575 \\
\hline Barranquilla/Ma & $\begin{array}{l}0,0108 \\
(0,012)\end{array}$ & 0,050 & $\begin{array}{c}-0,0051 \\
(0,001)^{\star \star}\end{array}$ & 0,367 & $\begin{array}{l}-0,0023 \\
(0,001)^{\star \star}\end{array}$ & 0,125 \\
\hline Barranqu & $\begin{array}{c}-0,0120 \\
(0,012)\end{array}$ & 0,059 & $\begin{array}{c}-0,0025 \\
(0,001)^{\star *}\end{array}$ & 0,086 & $\begin{array}{c}-0,0050 \\
(0,001)^{\star \star \star}\end{array}$ & 0,223 \\
\hline Barranquilla/P & $\begin{array}{c}-0,0577 \\
(0,014)^{\star \star \star}\end{array}$ & 0,494 & $\begin{array}{c}-0,0035 \\
(0,002)\end{array}$ & 0,061 & $\begin{array}{l}0,0032 \\
(0,002)\end{array}$ & 0,032 \\
\hline Buca & $\begin{array}{l}0,0086 \\
(0,011)\end{array}$ & 0,039 & $\begin{array}{c}-0,0115 \\
(0,001)^{\star \star \star}\end{array}$ & 0,669 & $\begin{array}{c}-0,0005 \\
(0,001) \\
-0,0047\end{array}$ & 0,003 \\
\hline Manizales/Buc & $\begin{array}{c}-0,0459 \\
(0,007)^{\star * \star}\end{array}$ & 0,757 & $\begin{array}{l}0,0024 \\
(0,002)\end{array}$ & 0,062 & $\begin{array}{l}-0,0047 \\
(0,002)^{\star \star}\end{array}$ & 0,139 \\
\hline Medellí & $\begin{array}{c}-0,0231 \\
(0,007)^{\star \star \star}\end{array}$ & 0,423 & $\begin{array}{l}0,0017 \\
(0,001)\end{array}$ & 0,037 & $\begin{array}{c}-0,0046 \\
(0,001)^{\star \star \star}\end{array}$ & 0,219 \\
\hline Pasto & $\begin{array}{c}0,0168 \\
(0,014)\end{array}$ & 0,082 & $\begin{array}{l}-0,0030 \\
(0,002)\end{array}$ & 0,078 & $\begin{array}{c}-0,0110 \\
(0,002)^{\star \star \star}\end{array}$ & 0,362 \\
\hline Manizal & $\begin{array}{l}-0,0127 \\
(0,007)^{*}\end{array}$ & 0,154 & $\begin{array}{c}-0,0058 \\
(0,001)^{\star \star \star}\end{array}$ & 0,556 & $\begin{array}{c}-0,0061 \\
(0,001)^{\star \star \star}\end{array}$ & 0,589 \\
\hline ín/Cali. & $\begin{array}{c}0,0095 \\
(0,008)\end{array}$ & 0,086 & $\begin{array}{c}-0,0077 \\
(0,001)^{\star \star \star}\end{array}$ & 0,605 & $\begin{array}{c}-0,0060 \\
(0,001)^{\star \star \star}\end{array}$ & 0,398 \\
\hline Cali & $\begin{array}{c}-0,0749 \\
(0,013)^{\star * *}\end{array}$ & 0,690 & $\begin{array}{c}-0,0013 \\
(0,0021)^{\star \star \star}\end{array}$ & 0,343 & $\begin{array}{c}-0,0097 \\
(0,001)^{\star \star \star}\end{array}$ & 0,450 \\
\hline Man & $\begin{array}{c}-0,0228 \\
(0,007)^{\star \star \star *}\end{array}$ & 0,440 & $\begin{array}{l}-0,0020 \\
(0,001)^{\star}\end{array}$ & 0,074 & $\begin{array}{l}-0,0016 \\
(0,001)\end{array}$ & 0,043 \\
\hline Man & $\begin{array}{c}-0,0771 \\
(0,012)^{\star \star \star}\end{array}$ & 0,719 & $\begin{array}{l}0,0015 \\
(0,002)\end{array}$ & 0,016 & $\begin{array}{l}0,0025 \\
(0,002)\end{array}$ & 0,045 \\
\hline Med & $\begin{array}{c}-0,0542 \\
(0,013)^{\star \star \star}\end{array}$ & 0,520 & $\begin{array}{r}0,0008 \\
(0,002) \\
\end{array}$ & 0,005 & $\begin{array}{c}0,0044 \\
(0,002)^{\star \star}\end{array}$ & 0,126 \\
\hline
\end{tabular}

1 Para el período 1950-1990, la razón de precios es Bogotá/Bucaramanga para la patata, para el período 1950-1990, la razón de precios es Pasto/Bogotá para la panela.

Notas: Desviaciones standard en paréntesis, * significativo al 10 por $100,{ }^{* *}$ significativo al 5 por $100,{ }^{* *}$ significativo al 1 por 100 . 


\section{CUADRO 7 (Cont.)}

Convergencia de precios entre ciudades. Producto: Sal

\begin{tabular}{|c|c|c|c|c|c|c|}
\hline \multirow{2}{*}{$\begin{array}{l}\text { Razones de precios } \\
\text { entre ciudades } \\
\text { In }\left(P_{B} / P_{A}\right)\end{array}$} & \multicolumn{2}{|c|}{$1928-1950$} & \multicolumn{2}{|c|}{$1950-1990$} & \multicolumn{2}{|c|}{$1928-1990$} \\
\hline & $\begin{array}{c}\text { Tasa de } \\
\text { convergencia }(\beta)\end{array}$ & $R^{2}$ & $\begin{array}{c}\text { Tasa de } \\
\text { convergencia }(\beta)\end{array}$ & $R^{2}$ & $\begin{array}{c}\text { Tasa de } \\
\text { convergencia }(\beta)\end{array}$ & $R^{2}$ \\
\hline Bogotá/Barranquilla ........ & $\begin{array}{l}-0,0092 \\
(0,005)^{*}\end{array}$ & 0,155 & $\begin{array}{c}-0,0029 \\
(0,004)\end{array}$ & 0,020 & $\begin{array}{c}-0,0061 \\
(0,002)^{\star \star \star}\end{array}$ & 0,199 \\
\hline Bucaramanga/Bogotá .......... & $\begin{array}{c}-0,0212 \\
(0,005)^{* * \pi}\end{array}$ & 0,520 & $\begin{array}{c}-0,0079 \\
(0,002)^{* * * *}\end{array}$ & 0,311 & $\begin{array}{c}-0,0036 \\
(0,001)^{* * *}\end{array}$ & 0,106 \\
\hline Bogotá/Cali & $\begin{array}{l}-0,0165 \\
(0,007)^{\star \star}\end{array}$ & 0,239 & $\begin{array}{c}-0,0004 \\
(0,002)\end{array}$ & 0,001 & $\begin{array}{r}-0,0024 \\
(0,001)^{\star \star}\end{array}$ & 0,079 \\
\hline Manizales/Bogotá.. & $\begin{array}{c}-0,0099 \\
(0,007)\end{array}$ & 0,106 & $\begin{array}{c}0,0013 \\
(0,002)\end{array}$ & 0,009 & $\begin{array}{c}0,0001 \\
(0,001)\end{array}$ & 0,003 \\
\hline Medellín/Bogotá................... & $\begin{array}{c}-0,0282 \\
(0,001)^{\star * *}\end{array}$ & 0,329 & $\begin{array}{c}-0,0018 \\
(0,002)\end{array}$ & 0,023 & $\begin{array}{c}-0,0031 \\
(0,003)\end{array}$ & 0,087 \\
\hline Pasto/Bogotá ........................... & $\begin{array}{c}-0,0014 \\
(0,014)\end{array}$ & 0,006 & $\begin{array}{l}-0,0089 \\
(0,003)^{\star \star}\end{array}$ & 0,176 & $\begin{array}{l}-0,0008 \\
(0,002)\end{array}$ & 0,003 \\
\hline Bucaramanga/Barranquilla. & $\begin{array}{c}-0,0154 \\
(0,006)^{\star * t}\end{array}$ & 0,272 & $\begin{array}{l}-0,0045 \\
(0,003)^{\star}\end{array}$ & 0,077 & $\begin{array}{c}-0,0097 \\
(0,002)^{* * *}\end{array}$ & 0,353 \\
\hline Cali/Barranquilla ................. & $\begin{array}{c}-0,0221 \\
(0,005)^{* * *}\end{array}$ & 0,444 & $\begin{array}{l}0,0030 \\
(0,003)\end{array}$ & 0,024 & $\begin{array}{c}-0,0086 \\
(0,002)^{\star \star \star}\end{array}$ & 0,342 \\
\hline Manizales/Barranquilla....... & $\begin{array}{c}-0,0073 \\
(0,004)^{* * *}\end{array}$ & 0,161 & $\begin{array}{l}-0,0021 \\
(0,003)\end{array}$ & 0,015 & $\begin{array}{c}-0,0059 \\
(0,001)^{\star * *}\end{array}$ & 0,274 \\
\hline Medellín/Barranquilla ........ & $\begin{array}{c}-0,0224 \\
(0,008)^{\star \star \star *}\end{array}$ & 0,318 & $\begin{array}{c}-0,0016 \\
(0,003)\end{array}$ & 0,010 & $\begin{array}{c}-0,0092 \\
(0,001)^{\star \star \star}\end{array}$ & 0,429 \\
\hline Pasto/Barranquilla.. & $\begin{array}{c}0,0044 \\
(0,01)\end{array}$ & 0,006 & $\begin{array}{c}-0,0055 \\
(0,002)^{\star *}\end{array}$ & 0,125 & $\begin{array}{c}-0,0025 \\
(0,002)\end{array}$ & 0,027 \\
\hline Bucaramanga/Cali.. & $\begin{array}{c}-0,0085 \\
(0,004)^{* *}\end{array}$ & 0,191 & $\begin{array}{c}-0,0075 \\
(0,001)^{* * *}\end{array}$ & 0,470 & $\begin{array}{c}-0,0011 \\
(0,001)\end{array}$ & 0,021 \\
\hline Bucaramanga/Manizales .... & $\begin{array}{l}-0,0232 \\
(0,004)^{\star * *}\end{array}$ & 0,592 & $\begin{array}{c}-0,0066 \\
(0,002)^{\star \star \star}\end{array}$ & 0,261 & $\begin{array}{c}-0,0037 \\
(0,001)^{\star * *}\end{array}$ & 0,121 \\
\hline Bucaramanga/Medellin ...... & $\begin{array}{l}-0,0082 \\
(0,006)\end{array}$ & 0,076 & $\begin{array}{c}-0,0061 \\
(0,001)^{\star \star *}\end{array}$ & 0,549 & $\begin{array}{l}-0,0005 \\
(0,001)\end{array}$ & 0,004 \\
\hline Pasto/Bucaramanga ............. & $\begin{array}{c}-0,0032 \\
(0,007)^{* *}\end{array}$ & 0,009 & $\begin{array}{c}0,0008 \\
(0,002)\end{array}$ & 0,004 & $\begin{array}{c}0,0027 \\
(0,002)\end{array}$ & 0,063 \\
\hline Cali/Manizales.................... & $\begin{array}{c}-0,0148 \\
(0,005)^{\star \star \star}\end{array}$ & 0,286 & $\begin{array}{l}0,0008 \\
(0,002)\end{array}$ & 0,007 & $\begin{array}{c}-0,0026 \\
(0,001)^{* * *}\end{array}$ & 0,092 \\
\hline Cali/Medellín.. & $\begin{array}{l}0,0117 \\
(0,009)\end{array}$ & 0,090 & $\begin{array}{c}0,0014 \\
(0,001)\end{array}$ & 0,048 & $\begin{array}{l}0,0006 \\
(0,001)\end{array}$ & 0,006 \\
\hline Pasto/Cali . & $\begin{array}{l}-0,0001 \\
(0,006)\end{array}$ & 0,001 & $\begin{array}{c}-0,0093 \\
(0,003)^{* * *}\end{array}$ & 0,275 & $\begin{array}{l}0,0016 \\
(0,002)\end{array}$ & 0,017 \\
\hline Medellín/Manizales ............. & $\begin{array}{c}-0,0183 \\
(0,006)^{* * *}\end{array}$ & 0,394 & $\begin{array}{c}-0,0005 \\
(0,002)\end{array}$ & 0,003 & $\begin{array}{c}-0,0032 \\
(0,001)^{* * * *}\end{array}$ & 0,168 \\
\hline Pasto/Manizales ..................... & $\begin{array}{l}0,0085 \\
(0,013)\end{array}$ & 0,026 & $\begin{array}{c}-0,0081 \\
(0,002)^{* * *}\end{array}$ & 0,280 & $\begin{array}{l}-0,0010 \\
(0,001)\end{array}$ & 0,006 \\
\hline Pasto/Medellín ..................... & $\begin{array}{c}-0,0050 \\
(0,010)\end{array}$ & 0,010 & $\begin{array}{c}-0,0078 \\
(0,003)^{* * *}\end{array}$ & 0,221 & $\begin{array}{l}0,0022 \\
(0,002)\end{array}$ & 0,023 \\
\hline
\end{tabular}

Notas: Desviaciones standard en paréntesis, * significativo al 10 por $100,{ }^{* *}$ significativo al 5 por $100,{ }^{* * *}$ significativo al 1 por 100 . 


\section{CUADRO 7 (Cont.)}

Convergencia de precios entre ciudades. Producto: Azúcar

\begin{tabular}{|c|c|c|c|c|c|c|}
\hline \multirow{2}{*}{$\begin{array}{l}\text { Razones de precios } \\
\text { entre ciudades } \\
\ln \left(P_{B} P_{A}\right)\end{array}$} & \multicolumn{2}{|l|}{$1928-1950$} & \multicolumn{2}{|l|}{$1950-1990$} & \multicolumn{2}{|l|}{$1928-1990$} \\
\hline & $\begin{array}{c}\text { Tasa de } \\
\text { convergencia }(\beta)\end{array}$ & $R^{2}$ & $\begin{array}{c}\text { Tasa de } \\
\text { convergencia }(\beta)\end{array}$ & $R^{2}$ & $\begin{array}{c}\text { Tasa de } \\
\text { convergencia }(\beta)\end{array}$ & $R^{2}$ \\
\hline Bogotá/Barranquilla . & $\begin{array}{r}-0,0044 \\
(0,002)^{* *}\end{array}$ & 0,200 & $\begin{array}{c}-0,0012 \\
(0,001)\end{array}$ & 0,058 & $\begin{array}{c}-0,0026 \\
(0,001)^{\star * *}\end{array}$ & 0,374 \\
\hline Bucaramanga/Bogotá .......... & $\begin{array}{c}-0,0018 \\
(0,004)\end{array}$ & 0,014 & $\begin{array}{c}0,0009 \\
(0,001)\end{array}$ & 0,048 & $\begin{array}{c}-0,0007 \\
(0,001)\end{array}$ & 0,042 \\
\hline Bogotá/Cali ....... & $\begin{array}{c}0,0052 \\
(0,004)\end{array}$ & 0,111 & $\begin{array}{c}-0,0022 \\
(0,001)^{\star * \star}\end{array}$ & 0,245 & $\begin{array}{l}0,0007 \\
(0,001)\end{array}$ & 0,020 \\
\hline Manizales/Bogotá. & $\begin{array}{c}-0,0008 \\
(0,001)\end{array}$ & 0,012 & $\begin{array}{c}-0,0034 \\
(0,001)^{\star \star \star}\end{array}$ & 0,211 & $\begin{array}{c}-0,0010 \\
(0,001)\end{array}$ & 0,042 \\
\hline Bogotá/Me & $\begin{array}{c}0,0014 \\
(0,003)\end{array}$ & 0,012 & $\begin{array}{l}-0,0022 \\
(0,001)^{\star}\end{array}$ & 0,072 & $\begin{array}{c}-0,0030 \\
(0,001)^{\star \star \star *}\end{array}$ & 0,252 \\
\hline Pasto/Bogotá . & $\begin{array}{c}0,0064 \\
(0,006)\end{array}$ & 0,070 & $\begin{array}{c}-0,0014 \\
(0,001)\end{array}$ & 0,035 & $\begin{array}{l}-0,0012 \\
(0,001)\end{array}$ & 0,037 \\
\hline Bucaramanga/Barranquilla. & $\frac{-0,0062}{(0,003)^{* *}}$ & 0,199 & $\begin{array}{c}-0,0022 \\
(0,001)^{\star \star \star *}\end{array}$ & 0,275 & $\begin{array}{c}-0,0038 \\
(0,001)^{\star \star \star}\end{array}$ & 0,547 \\
\hline Cali/Bar & $\begin{array}{c}-0,0095 \\
(0,004)^{\star \star}\end{array}$ & 0,258 & $\begin{array}{c}-0,0014 \\
(0,001)\end{array}$ & 0,055 & $\begin{array}{l}0,0009 \\
(0,001)\end{array}$ & 0,031 \\
\hline Manizales/Barranquilla ${ }^{1}$.. & $\begin{array}{c}-0,0052 \\
(0,002)^{\star \star}\end{array}$ & 0,250 & $\begin{array}{l}-0,0022 \\
(0,001)^{*}\end{array}$ & 0,082 & $\begin{array}{l}-0,0016 \\
(0,001)^{\star}\end{array}$ & 0,084 \\
\hline Medellín/I & $\begin{array}{l}-0,0058 \\
(0,003)^{\star \star}\end{array}$ & 0,173 & $\begin{array}{l}-0,0004 \\
(0,001)\end{array}$ & 0,005 & $\begin{array}{l}0,0003 \\
(0,001)\end{array}$ & 0,001 \\
\hline Pasto/Barr & $\begin{array}{c}-0,0108 \\
(0,005)^{*}\end{array}$ & 0,212 & $\begin{array}{l}0,0004 \\
(0,002)\end{array}$ & 0,002 & $\begin{array}{c}-0,0046 \\
(0,001)^{\star * \star} \\
-0,0009\end{array}$ & $\begin{array}{l}0,288 \\
0,038\end{array}$ \\
\hline Bucaramar & $\begin{array}{l}0,0034 \\
(0,005)\end{array}$ & 0,025 & $\begin{array}{c}-0,0035 \\
(0,001)^{\star \star *} \\
-0,0044\end{array}$ & $\begin{array}{l}0,307 \\
0,271\end{array}$ & $\begin{array}{c}-0,0009 \\
(0,001) \\
-0,0019\end{array}$ & 0,143 \\
\hline Bucaramar & $\begin{array}{c}-0,0010 \\
(0,002)\end{array}$ & 0,010 & $\begin{array}{c}-0,0044 \\
(0,001)^{* * *}\end{array}$ & $0,2 / 1$ & $\begin{array}{c}(0,001)^{\star \star *} \\
-0,0044\end{array}$ & 0,442 \\
\hline Bucaramar & $\begin{array}{c}-0,0004 \\
(0,004)\end{array}$ & 0,005 & $\begin{array}{c}-0,0026 \\
(0,001)^{\star \star \star}\end{array}$ & $0,14\rangle$ & $\begin{array}{c}(0,001)^{* * *} \\
-0,0008\end{array}$ & 0,019 \\
\hline Pasto/Buca & $\begin{array}{c}-0,0046 \\
(0,005)\end{array}$ & 0,051 & $\begin{array}{l}-0,0019 \\
(0,001)\end{array}$ & $\begin{array}{l}0,048 \\
0,048\end{array}$ & $\begin{array}{l}(0,001) \\
-0,0012\end{array}$ & 0,057 \\
\hline Cali/Man & $\begin{array}{c}-0,0043 \\
(0,004)\end{array}$ & 0,060 & $\begin{array}{c}0,0013 \\
(0,001) \\
-0,0010\end{array}$ & $\begin{array}{l}0,048 \\
0,001\end{array}$ & $\begin{array}{l}(0,001)^{\star} \\
-0,0037\end{array}$ & 0,222 \\
\hline Cali/Medellín ${ }^{1}$ & $\begin{array}{l}-0,0083 \\
(0,004)^{* \star}\end{array}$ & 0,255 & $\begin{array}{c}-0,0010 \\
(0,001) \\
0,0003\end{array}$ & 0,001 & $\begin{array}{c}(0,001)^{* * *} \\
-0,0009\end{array}$ & 0,016 \\
\hline Pasto/Cali & $\begin{array}{l}0,0012 \\
(0,007)\end{array}$ & 0,002 & $\begin{array}{c}0,0003 \\
(0,001) \\
0,0017\end{array}$ & 0,037 & $\begin{array}{c}(0,001) \\
-0,0022\end{array}$ & 0,095 \\
\hline Medellin/Manizales. & $\begin{array}{r}-0,0071 \\
(0,003)^{* *}\end{array}$ & 0,212 & $\begin{array}{c}0,0011 \\
-0,001)\end{array}$ & 0,021 & $\begin{array}{c}(0,001)^{\star *} \\
-0,0027\end{array}$ & 0,128 \\
\hline Pasto/Man & $\begin{array}{c}-0,0055 \\
(0,005) \\
-0,0050 \\
(0,006)\end{array}$ & $\begin{array}{l}0,064 \\
0,038\end{array}$ & $\begin{array}{l}(0,002) \\
-0,0024 \\
(0,001)\end{array}$ & 0,001 & $\begin{array}{c}(0,001)^{\star \star \star} \\
-0,0042 \\
(0,001)^{\star \star \star}\end{array}$ & 0,269 \\
\hline
\end{tabular}

1 Para el período 1950-1990, la razón de precios es Barranquilla/Manizales para el azúcar, para el periodo 1950, la razón de precios es Medellin/Cali para el azúcar.

Notas: Desviaciones standard en paréntesis, ${ }^{*}$ significativo al 10 por $100,{ }^{* *}$ significativo al 5 por $100, * * *$ significativo al 1 por 100 . 


\section{CONCLUSIÓN}

A diferencia de otros países latinoamericanos, como Brasil y México, en Colombia la construcción de los ferrocarriles no jugó un papel primordial en el crecimiento económico. A diferencia de éstos, la magnitud del ahorro social no fue considerable, y su influencia tanto en la integración del mercado interno como en la expansión del externo no fue excepcional. El problema radicó en que los ferrocarriles en Colombia se construyeron muy tarde. El auge en la construcción de ferrocarriles coincidió con la época en la cual el desarrollo del transporte automotor estaba tomando impulso y por esta razón las carreteras reemplazaron rápidamente a los ferrocarriles. Esto sumado al hecho de que se extendieron pocos kilómetros de red férrea, las líneas estaban físicamente separadas y el tamaño de la trocha era distinto entre ferrocarriles; por lo tanto, el país no contó con un sistema férreo que comunicara de forma eficiente las diferentes regiones colombianas.

\section{ANEXO}

Modelo que incluye el log de las exportaciones de café y el log de los kilómetros de ferrocarriles: 1905-1955

\begin{tabular}{|c|c|c|}
\hline \multicolumn{3}{|c|}{ Test de Dickey y Fuller Aumentado } \\
\hline & Café & Ferrocarriles \\
\hline $\begin{array}{l}\text { Variable dependiente }(\mathrm{t}-1) \\
\text { (t-estadístico) }\end{array}$ & $\begin{array}{l}-0,4324 \\
(-3,19)\end{array}$ & $\begin{array}{l}-0,0833 \\
(-4,45)\end{array}$ \\
\hline (t-estadístico) & $\begin{array}{l}2,7702 \\
(3,26)\end{array}$ & $\begin{array}{l}0,6357 \\
(4,64)\end{array}$ \\
\hline Tendencia & $\begin{array}{c}0,0232 \\
(3,01)\end{array}$ & \\
\hline Número de rezagos & 0 & 2 \\
\hline 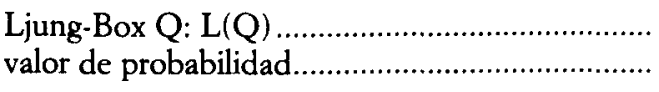 & $\begin{array}{l}\mathrm{L}(11)=9,45 \\
0,58\end{array}$ & $\begin{array}{l}\mathrm{L}(11)=5,27 \\
0,92\end{array}$ \\
\hline 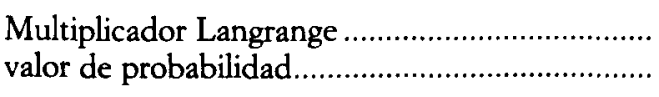 & $\begin{array}{c}\mathrm{LM}(4)=1,213 \\
0,3198\end{array}$ & $\begin{array}{c}\mathrm{LM}(4)=0,331 \\
0,8553\end{array}$ \\
\hline 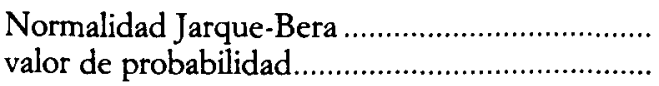 & $\begin{array}{l}0,2924 \\
0,8639\end{array}$ & $\begin{array}{c}4,56 \\
0,1022\end{array}$ \\
\hline
\end{tabular}

Nota: El valor critico de Mackinnon del 10 por 100 para rechazar la hipótesis nula de presencia de raíz unitaria es: $-3,1828$. 
Criterio de información para obtener el rezago óptimo

\begin{tabular}{cccc}
\hline $\begin{array}{c}\text { Numero de rezagos } \\
(p)\end{array}$ & $\begin{array}{c}\text { Akaike } \\
(\mathrm{AIC})\end{array}$ & $\begin{array}{c}\text { Schwarts } \\
(\mathrm{SC})\end{array}$ & $\begin{array}{c}\text { Hannan-Quinn } \\
(\mathrm{HQ})\end{array}$ \\
\hline 1 & $-9,9332^{*}$ & $-9,7649^{*}$ & $-9,8729^{*}$ \\
2 & $-9,8321$ & $-9,5044$ & $-9,7113$ \\
3 & $-9,7631$ & $-9,2715$ & $-9,5818$ \\
4 & $-9,6848$ & $-9,0294$ & $-9,4431$ \\
5 & $-9,6194$ & $-8,8002$ & $-9,3173$ \\
\hline
\end{tabular}

Nota: El orden de $p$ es escogido como aquel que minimiza el valor del criterio.

Test de Portmanteau para autocorrelación

\begin{tabular}{ccc}
\hline $\begin{array}{c}\text { Numero de rezagos } \\
(p)\end{array}$ & Estadístico & Probabilidad \\
\hline 1 & 44,03 & 0,4703 \\
2 & 44,05 & 0,3041 \\
3 & 41,61 & 0,2398 \\
4 & 40,71 & 0,1389 \\
\hline
\end{tabular}

Nota: Hipótesis nula: los residuos son ruido blanco.

Test multivariado de normalidad

\begin{tabular}{cll}
\hline $\begin{array}{c}\text { Número de rezagos } \\
(p)\end{array}$ & Estadístico & Probabilidad \\
\hline \multirow{2}{*}{1} & $\lambda_{1}=0,7866$ & 0,6748 \\
& $\lambda_{2}=2,6752$ & 0,2647 \\
& $\lambda_{3}=3,4618$ & 0,4837 \\
2 & $\lambda_{1}=7,1789$ & 0,0276 \\
& $\lambda_{2}=2,3679$ & 0,3061 \\
& $\lambda_{3}=9,5468$ & 0,0587 \\
3 & $\lambda_{1}=2,7652$ & 0,2509 \\
& $\lambda_{2}=0,3034$ & 0,8593 \\
& $\lambda_{3}=3,0685$ & 0,5464 \\
4 & $\lambda_{1}=1,9766$ & 0,3722 \\
& $\lambda_{2}=2,3409$ & 0,3102 \\
& $\lambda_{3}=4,3175$ & 0,3647 \\
\hline
\end{tabular}

Nota: El test se basa en el tercer y cuarto momento de la distribución normal. Hipótesis nula: el proceso generador de los datos es normal. 


\section{BIBLIOGRAFÍA}

Arias de Greiff, G. (1986): La Mula de Hierro, Carlos Valencia Editores.

Barnhart, D. (1956): Colombian Transportation Problems and Policies, 1923-1948, $\mathrm{Ph}$. D. Dissertation, University of Chicago.

Bateman, A. (1986): «La Ingeniería, las Obras Públicas y el Transporte en Colombia», en Historia Extensa de Colombia, vol. XXI.

BEYER, R. C. (1947): The Colombian Coffee Industry: Origins and Major Trends 1740-1940, Ph. D. Dissertation, University of Minnesota.

Charemza, W. W., y Derek, F. D. (1997): New Directions in Econometric Practice: General to Specific Modelling, Cointegration and Vector Autoregression, Second Edition, Edward Elgar Publishing Limited.

COATsworth, J. (1981): Growth Against Development: The Economic Impact of Railroads in Porfirian Mexico, Northern Illinois University Press, De Kalb.

Contraloría General: Anuario General de Estadística, varios años.

Consejo Administrativo de los Ferrocarriles Nacionales: Revista del Consejo Administrativo de los Ferrocarriles Nacionales, 1932-1934.

Currie, L. (1951): Bases de un Programa de Fomento para Colombia: Informe de una Misión, 2. ${ }^{a}$ ed., BIRF-Banco de la República.

Departamento Administrattvo Nacional de Estadistica (1982): Índice de Precios al Consumidor: 1954-1978, DANE.

- Anuario General de Estadística, varios años.

- Boletin Mensual de Estadística, varios años.

- Los Ferrocarriles en Cifras, varios años.

Departamento Nacional de Planeación, 1978. Documento 1473-UNIF-UIP.

ENDERS, W. (1995): Applied Econometric Time Series, First Edition, John Wiley \& Sons, INC.

FisHLOW, A. (1965): American Railroads and the Transformation of the Ante-bellum Economy, Harvard University Press.

FOGEL, R. (1964): Railroads and American Economic Growth: Essays in Econometric History, The Johns Hopkins Press.

- (1979): «Notes on the Social Saving Controversy», Joumal of Economic History, $10,12-51$.

Gómez, A. (1982): Ferrocarriles y Cambio Económico en España: 1855-1913, Alianza Universidad Editores.

GreEN, W. H. (1993): Econometric Analysis, capítulo 16, 2. a ed., Macmillan Publishing Company.

Grupo de Estudios del Crecimiento Económico (1997): «El Desempeño Macroeconómico Colombiano: Series Estadísticas 1905-1997», Borradores Semanales de Economía, Banco de la República.

GuAJARDO, G. (1998): «Nuevos datos para un viejo debate: los vínculos entre ferrocarriles e industrialización en Chile y México (1860-1950)», El Trimestre Económico, 65(2), abril-junio.

HAWKE, G. R. (1983): «Britain», en Railways and the Economic Development of Western Europe, 1830-1914, editado por Patrick O'Brien, St. Antony's College, Oxford-Macmillan Series. 
HsiaO, C. (1995): Analysis of Panel Data, Econometric Society Monographs \#No 11, Cambridge University Press.

Jugde, G.; Griffiths, W. E.; Carter, H.; Lutkrohl, H., y Tsoung-Chao, L. (1985): The Theory and Practice of Econometrics, chapter 13, John Wiley and Sons, second edition.

Junguito, R., y Pizano, D. (eds.) (1991): Producción de Café en Colombia, Fedesarrollo y Fondo Cultural Cafetero.

Latorre, E. (1986): El Transporte y el Crecimiento Regional en Colombia, Bogotá, Universidad de los Andes.

LEBRET, J. (1958): Misión de Economia y Humanismo, Bogotá.

LÜTKEPOHL, H. (1991): Introduction to multiple time series analysis, Capítulo 4, Springer-Verlag, Berlin-Heidelberg.

Meisel, A. (1999): «La cliometría en Colombia: Una revolución interrumpida, 1971-1999», Revista de Historia Económica, Año XVII, Número especial.

McGreevey, W. P. (1975): Historia Económica de Colombia: 1845-1930, Tercer Mundo Editores.

Ministerio de Agricultura: Anuario Estadístico, varios años.

Ministerio de Obras Públicas y Transporte: Memorias del Ministro, varios años.

Ministerio de TRANSPORTE (1995): El Transporte en Cifras: 1970-1994, Imprenta Nacional.

OCAMPO, J. A. (1984): Colombia y la Economía Mundial, 1830-1900

O'Brien, A. P. (1977): The New Economic History of the Railways, New York, St. Martin's Press.

OrtegA, A. (1932): Ferrocarriles Colombianos: La Última Experiencia Ferroviaria del País: 1920-1930, Imprenta Nacional.

Oum, T. H.; Waters, W. G. II, y Yong, J. S (1990): «A Survey of Recent Estimates of Price Elasticities of Demand for Transport», The World Bank, Working Papers Series, núm. 359, January.

Palacios, M. (1980): Coffee in Colombia, 1850-1970: An economic, social, and political bistory, Cambridge University Press.

PovedA, G. (1974): Antioquia y el Ferrocarril de Antioquia.

- (1986): «Nuestra Historia Ferroviaria», Revista Antioqueña de Economía y Desarrollo, 20.

RAmirez, M. T. (1999): On Infrastructure and Economic Growth, Ph. D. Dissertation, University of Illinois at Urbana-Champaign.

RATS, (1996): User's Manual, version 4.2.

Slaughter, M. J. (1995): «The Ante-bellum Transportation Revolution and Factor-Price Convergence», NBER Working Papers Series No 5303.

SOCiedad Colombiana de InGenieros, Anales de Ingenieria, varios años.

Summerhill, W. R. (1995): Railroads and the Brazilian Economy Before 1914, Ph. D. Dissertation, Stanford University.

- (1996): «The Political Economy of Subsidy and Regulation: Railroads in Imperial Brazil», UCLA, mimeo.

- (1997): «Transport Improvements and Economic Growth in Brazil and Mexico», Stephen Haber, ed., How Latin American Fell Behind, Stanford University Press. 
Urrutia, M., y Arrubla, M. (eds.) (1970): Compendio de Estadísticas Históricas de Colombia, Universidad Nacional de Colombia.

UrRuTIA, M. (1979): «La Creación de las Condiciones Iniciales para el Desarrollo: El Café», en 50 Años de Desarrollo Económico Colombiano, La Carreta, Inéditos Ltda. 